\title{
Seres mitologicos y figuras alegóricas en los mosaicos romanos de Hispania en relación con el agua*
}

\author{
Mythological and allegorical subjects in the Roman mosaics in \\ Hispania related with water
}

\author{
M. PILAR SAN NICOLAS PEDRAZ \\ UNED (Madrid)
}

\begin{abstract}
RESUMEN
Análisis de los mosaicos hispanos con las representaciones de seres mitológicos y figuras alegóricas en relación con el agua que tienen su dispersión geográfica preferentemente en la Bética (provincia muy romanizada y que pronto tuvo carácter senatorial) y la Lusitania y en puntos aislados del levante y la mitad norte peninsular. En cuanto a sus contextos arquitectónicos corresponden a ambientes termales de carácter urbano, públicos o privados, y de carácter rústico, así como a fuentes o estanques; igualmente se encuentran decorando estancias de prestigio de las casas privadas o de las villae, especialmente en

o cerca del triclinium, oecus, tablinum, atrium, peristylum o de los cubicula. La cronología de estos mosaicos abarca desde el siglo II hasta el V, con un predominio de ejemplares en el Alto Imperio sobre la época Tardorromana. El ejemplar más antiguo de todos estos mosaicos es el de los tritones de la plaza de San Miguel de Barcelona, de tradición italiana, realizado en blanco y negro, que data de la primera mitad del siglo II y que pavimentaba unas termas públicas.
\end{abstract}

ABSTRACT

Analysis of the Hispanic mosaics with the depictions of mythological beings and allegorical figures related to water who have their geographical diffusion mainly in Baetica (a very Romanized province that would soon have a senatorial character), Lusitania, and in isolated areas in the east and the northern half of the Peninsula. With regard to their architectonic contexts they correspond to thermal surroundings of urban character, public or private, and of rustic character, as well as to springs and ponds. Likewise, they are found decorating rooms of prestige in private houses or in the villae, especially in or close to the triclinium, oecus, tablinum, atrium, peristylum or the cubicula.

The chronology of these mosaics spans from the second to the fifth century, with a predominance of representations in the High Empire over the Late Empire. The oldest example of all these mosaics is the one with the tritons in the square of San Miguel in Barcino (Barcelona), of Italian tradition, made in black and white and dated back to the first half of the second century, which paved some public thermal baths.

\footnotetext{
* Este trabajo se ha realizado dentro del Proyecto de Investigación HUM 2004- 01056.
} 
Dentro de la musivaria romana existe un conjunto destacado y relativamente variado de personajes mitológicos y de figuras alegóricas que tienen relación con las aguas. La mayoría de estas representaciones además de intervenir en distintos episodios de los relatos míticos, desarrollan habitualmente sus actividades en ambientes húmedos y tienen un significado especial por el valor profiláctico del agua como generadora de fertilidad y prosperidad.

En el primer grupo, seres mitológicos, hemos agrupado divinidades y otros personajes como tritones, nereidas, animales fantásticos y daimones. El otro grupo lo forman los pavimentos con las figuras de los ríos (Asopo, Aqueloo, Éufrates, Nilo...), las fuentes (Hipocrene y Amymone) y las ninfas (Metope, Amymone, Aretusa y Amaltea).

La cronología de estas representaciones abarca desde el siglo I a.C. hasta el v d.C.

De los ejemplares conocidos en contexto arqueológico, unos corresponden a ambientes termales ${ }^{1}$, de carácter urbano público (pav. de Tritones de San Miguel, Barcelona; el apodyterium o la cella unctuaria de la insula 30 de Ampurias). De carácter urbano privado (Triunfo de Neptuno de Itálica, espacio contiguo a una piscina con restos de una escalera y próximo a dos salas con hipocaustum en la ínsula comprendida entre la Casa de la Exedra y la Casa de los Pájaros; Astigi, Écija, mosaico con dos nereidas). Rústico (fragmento del pavimento del Tritón de La Cocosa, Badajoz, en el tepidarium; Nereida de El Hinojal, Augusta Emerita; Tritón de Santa Vitória do Ameixial, Portugal y posiblemente el pav. de Neptuno estatuario de La Salud, Sabadell, Barcelona)2 , y el mosaico de tritón de la villa de Fuente Alamo (Córdoba). Otros mosaicos pavimentaban fuentes o estanques (Tritón de Santiponce en Itálica; thiasos de El Chorreadero, Paterna, Cádiz) o diferentes estancias de prestigio de las mansiones residenciales urbanas: tablinum de la Casa de Venus, Itálica (Nacimiento de Venus); el de Océano de Carranque, Toledo; centro del ala sur del peristilo de la Casa de los Surtidores, Conimbriga, Portugal (pavimento con Tritón y el de Perseo) ${ }^{3}$, triclinium de una casa de Córdoba (mosaico de Polifemo y Galatea); junto al atrium tetrastilo de la Casa de Mitreo, en Augusta Emerita (mosaico Cosmológico); Casa de Aquiles de Complutum; Casa del Planetario de Itálica (dios-río). Sin determinar estancia dentro de ciudades (Triunfo de Neptuno de Augusta Emerita; tritón de Sasamón, Burgos; thiasos de

\footnotetext{
1 NeIRA JimÉneZ, M.L. «Mosaicos romanos con nereidas y tritones. Su relación con el ambiente arquitectónico en el Norte de Africa y en Hispania», L'Africa Romana X, 1994, págs. 1259- 1278; ID.: «Algunas consideraciones sobre mosaicos con nereidas y tritones en ambientes termales de Hispania», en Peréx, M.J. (ed.), Termalismo Antiguo (I Congreso Peninsular), Madrid, UNED- CV, 1997, págs. 481496.

${ }^{2}$ Su emplazamiento bajo el crucero de una antigua Iglesia así como su posible pertenencia a un edificio termal sería otro ejemplo de reutilización in situ de edificios termales en lugares de culto como ocurre en el pavimento, ya citado, de Tritones de la Iglesia de San Miguel en Barcelona, atribuido a un complejo termal de la antigua ciudad de Barcino, NeIRA JiMÉNEZ, M.L.: op. cit. nota 1, págs. 482 y 485.

${ }^{3}$ LóPEZ MonTEAGUDO, G.: «El programa iconográfico de la Casa de los Surtidores de Conimbriga», Espacio, Tiempo y Forma II/ 3, 1990, págs. 203-204, fig. 3; 209-210, fig. 7.
} 
Pompaelo; daimon de Astigi; nereida y Asopo en los mosaicos de Itálica), así como habitaciones concretas de las villae rurales: galería de Algorós, Alicante (Galatea); oecus con función de triclinium de El Pomar, Jerez de los Caballeros (pavimento del auriga vencedor con tritones); sala octogonal de Almenara de Adaja, Valladolid (Hipocrene en el pavimento de la «Toilette de Pegaso»); cubiculum principal de Carranque, Toledo (Pyramo y Thisbe del pavimento de Las Metamorfosis); podium del Santuario (nymphaeum) de Milreu, Portugal; habitación cruciforme independiente de Fuente Álamo, Córdoba (pavimento del río Nilo); habitación de prestigio de La Malena, Zaragoza (mosaico de las Bodas de Cadmo y Harmonia). Sin determinar estancia dentro de las villae (Neptuno de Puig de Cebolla, Valencia; Nacimiento de Venus de la Quintilla, Murcia (habitación 15, la más importante de la villa); Tethys de Bruñel, Jaén, aunque posiblemente por su forma absidal pertenezca al oecus; thiasos de Casariche, Sevilla; los dos mosaicos con monstruos marinos de la finca de Don R. Irles cerca de Illici, Asopo de Fernán Nuñez, Córdoba).

\section{SERES MITOLOGICOS}

\section{DIVINIDADES}

Entre ellas se encuentran los dioses propiamente de las aguas como Neptuno y Océano ${ }^{4}$ o los que algunos de sus episodios mitológicos tienen relación con ellas como ocurre con Venus, diosa del amor, que nace de la espuma y que navega sobre su concha. Así como otras divinidades menores tritones, nereidas... ya sean en solitario o formando grupo.

\footnotetext{
${ }^{4}$ Para el dios Océano véase de López Monteagudo, G.: «Oceanus on the Roman Mosaic Pavements of Spain». Proceedings of the Symposium 12 International Conferense 'Cura Aquarum in Ephesus', Leiden 2006, págs 497- 503; LóPEZ MONTEAGUDO, G.: «La iconografía del dios Océanos en los mosaicos hispano-romanos", $X^{\circ}$ Coloquio Internacional/Aiema. O Mosaico Antigonos centros e nos periferias: originalidades, influencias e identidades (Conímbriga, Portugal 2005), en prensa. En este trabajo que presentamos no hemos recogido las representaciones de la Medusa por que, aunque tiene relación con la iconografía marina al ser una de las tres Gorgonas nacida del mar y amante de Neptuno, suele aparecer, aparte de su episodio mitológico con Perseo, con las representaciones de Océano (mosaico de Córdoba; mosaico de Tarraco), BALIL, A.: «ll mosaico della Medusa di Tarragona», Hommages à Marcel Renard III, 1969, págs. 3- 13, lám. IV; BLÁZQUEZ, J.M.: Mosaicos romanos de Córdoba, Jaén y Málaga, CMRE III, Madrid 1981, págs. 22- 23, n. 6, figs. 1- 2, lám. 8; MondELO, R. y TORRES, M.: «El mosaico romano de Casariche (Sevilla)», BVallad LI, 1985, págs. 150-151. Para el episodio de la Medusa con Perseo vid. LóPez Monteagudo, G.: «El mito de Perseo en los mosaicos romanos. Particularidades hispanas», Espacio, Tiempo y Forma II/11, 1998, págs. 435- 491; ID.: «Perseo vencedor de la muerte», Miscelanea Lexica en Memoria de Conchita Serrano, Madrid 1999, págs. 637- 644; ID.,: «Perseo, viajero en Occidente», L'Africa Romana XIII, 2000, págs. 145- 157; VARGAS, S.: «La imagen de Medusa en los mosaicos romanos de Hispania», L'Africa Romana XVII (en prensa).
} 


\section{Neptuno}

De esta divinidad existen siete representaciones, con cuatro iconografías diferentes. En la primera aparece el dios guiando su carro tirado por dos hipocampos inmerso en una travesía marina, denominada «Triunfo de Neptuno». Esta escena se documenta en cuatro mosaicos del Alto Imperio, en Itálica (Sevilla) fechado en la segunda mitad del siglo $\|^{5}$ (Fig. 1), en Augusta Emerita de la primera mitad del siglo II $^{6}$, en Puig de Cebolla, Valencia de finales del siglo ${ }^{7}{ }^{7}$ y en el de Tarraco, del siglo II, estos dos últimos hoy desaparecidos. En los mosaicos de Itálica y Augusta Emerita el dios avanza hacia la derecha y está rodeado de un cortejo marino formado por peces variados, delfines, tritones, hipocampos..., que acentúan el apoteosis de la imagen. Mientras que el mosaico de Valencia en la travesía del dios se muestra únicamente el agua como marco del escenario marino. Las representaciones del «Triunfo de Neptuno» gozaron de gran auge en Italia en la

mu-

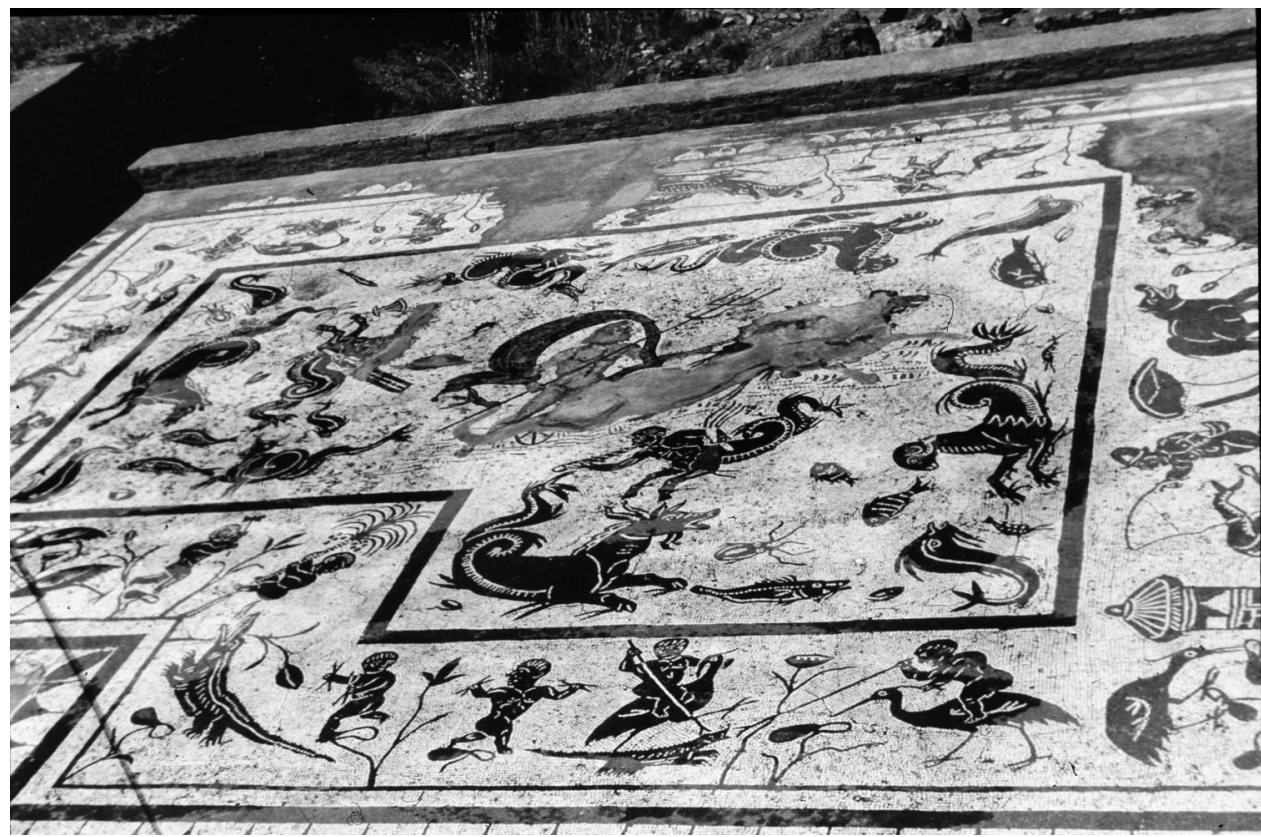

Fig. 1- Mosaico del «Triunfo de Neptuno» de Itálica. Segunda mitad del siglo II.

5 Blanco, A. y Luzón, J.M.: El mosaico de Neptuno en Itálica, Sevilla 1974; TorRes CarRo, M.: «Iconografía marina. Mosaicos romanos. Estudios sobre Iconografía». Actas de Homenaje in Memoriam de A. Balil, Madrid 1990, págs. 114-115; DuRÁN, M.: Iconografía de los mosaicos romanos en la Hispania alto-imperial, Barcelona 1993, págs. 226-263,

6 Blanco, A.: Mosaicos romanos de Mérida, CMRE II, Madrid 1978, págs. 29- 30, n 7, láms. 8- 10; Torres CARro, M.: op. cit. en nota 5, págs. 115-116, 121- 122.

7 LABORDE, A. (r. 1975): Viatge pintoresc i històric. El País Valencià $i$ les Illes Balears. (Original de 1806 editado en Paris). Valencia, pág. 265, dibujo n 40; BALIL, A.: «Los mosaicos de la villa romana de El Puig de Cebolla (Valencia)», IX Congreso Arqueológico Nacional (Valladolid 1965), Zaragoza 1966, págs. 336- 340 . 
sivaria bícroma de principios del Imperio, Ostia, Otricoli... y en Africa en mosaicos polícromos, Acholla, Timgad, Uthina, La Chebba, Hadrumentum, fechados a finales del siglo II y primera mitad del $11 \mathrm{I}^{8}$.

La segunda iconografía de Neptuno de la musivaria hispana aparece en el mosaico de la Villa de la Salud en Sabadell, de finales del siglo II o principios del III (Fig. 2). El tipo derivaría de un modelo escultórico griego de época helenística y aparece representado, además de en esculturas y relieves, en otros mosaicos, de los siglos II- IV, de Ostia, Comiso y Djemila (Túnez) ${ }^{10}$. En Hispania aparece en un bronce cántabro de Castro Urdiales ${ }^{11}$. La divinidad se representa en pie, de frente, con cetro en la mano izquierda y un tridente en la mano derecha. Junto a Neptuno

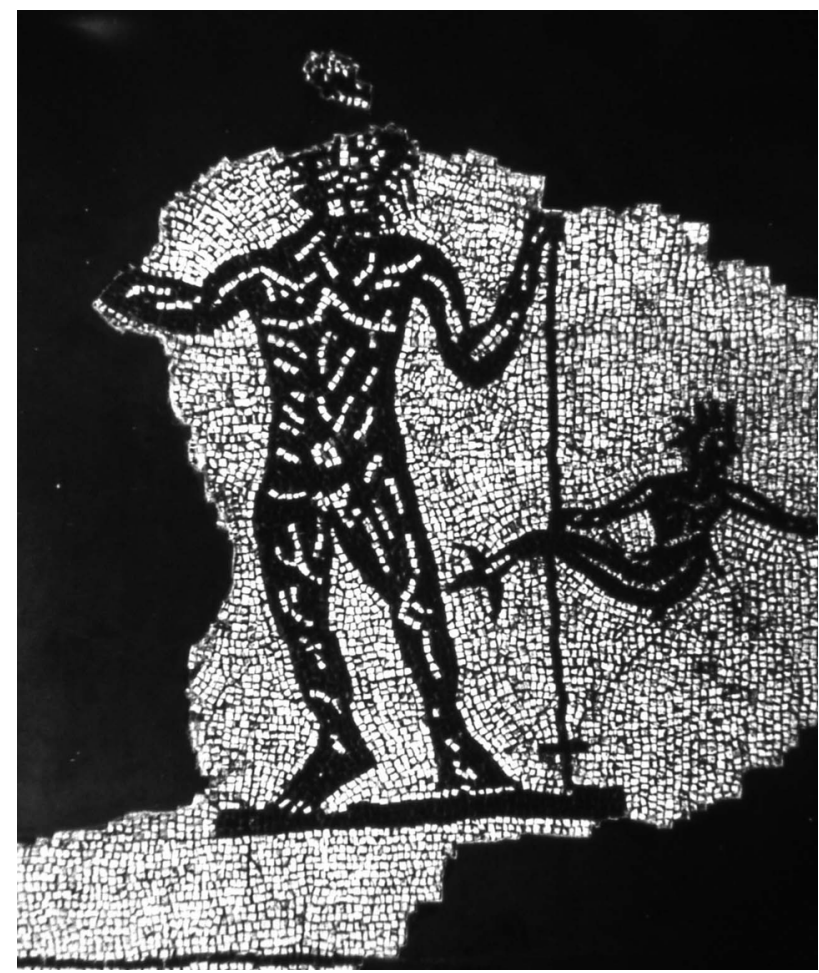

Fig. 2- Mosaico de Neptuno de la Villa de la Salud en Sabadell (Barcelona). Finales del siglo II o principios del III.

8 Para estos mosaicos véase NeIRA, M.L.: «La tipología del carro en los mosaicos romanos del triunfo de Neptuno», L'Africa Romana XI, 1996, págs. 555- 591.

9 BARRAL, X.: Les mosaïques romaines et mediévales de la Regio Laietana, Barcelona 1978, págs. 136- 138, n. 147, láms. XCV- XCVI.

10 BeCATtI, G.: Scavi di Ostia. Mosaici e Pavimenti IV, Roma 1961, 25, láms. CLXI- CLXII. ID.: «AIcune caratteristiche del mosaico blanco-nero in Italia», en CMGR II, Paris 1975, pág. 26, fig. 22; TORRES CARRO, M.: op. cit. en nota 5, págs. 116- 117.

11 Gonzalez Echegaray, J.: «El Néptuno cántabro de Urdiales», AEspA 30, 1957, pág. 253, n. 96, láms. 1-3. 
y en el lado izquierdo está representada una tritonesa, con el pelo erizado se sujeta al mango del tridente; la figura de la tritonesa es poco usual en la musivaria romana (infra).

La tercera iconografía de Neptuno aparece, sin procedencia, en la Colección Martí Estevez, en el Servicio de Investigación Arqueológica Municipal de Valencia (SIAM). Está representado de pie, en actitud de andar, con la cabeza girada hacia atrás, llevando un tridente en su mano derecha, como el bronce cántabro anteriormente citado, y un delfín en la mano izquierda (Fig. 3) ${ }^{12}$.

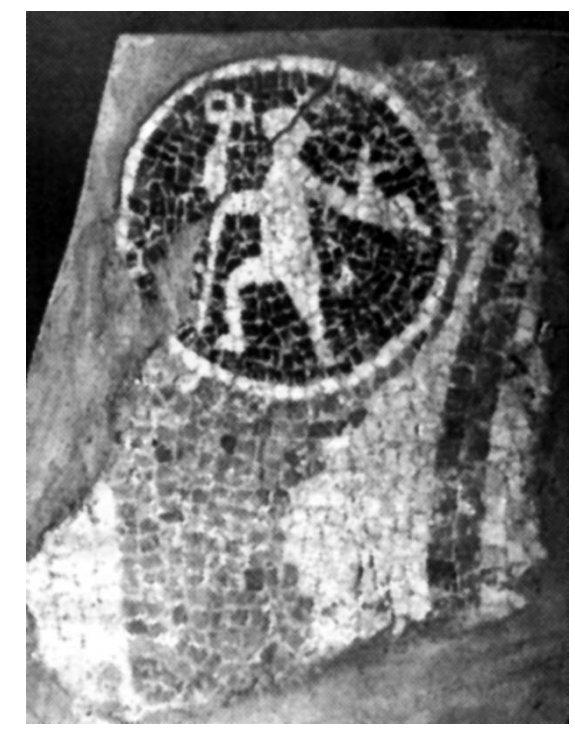

Fig. 3- Mosaico de Neptuno de procedencia desconocida, de la Colección Martí Estevez SIAM de Valencia.

La cuarta iconografía de Neptuno aparece en el espléndido mosaico del episodio mítico de las Bodas de Cadmo y Harmonia procedente de la villa de La Malena, en Azuara (Zaragoza), fechado en los siglos IV- $\mathrm{V}^{13}$. El dios, junto a otras divinidades, está representado en pie y de frente, ofreciendo la novia al futuro marido (Fig. 4). Este pavimento es un unicum en la musivaria romana.

12 CAStelL, V. (1976): «De la Valencia romana», Boletín de información Municipal, 3. Valencia, pág. 11; RIBERA, A. (1984): València romana. Els orígens de la ciutat. Valencia, pág. 43; PASIES OviEDO, T. (2004): Pavimentos musivos e época romana en la comunidad valenciana. Tratamientos y problemáticas asociadas a su conservación y restauración. Tesis Doctoral. Un. Politècnica de Valencia, pág. 203, fig. 295 (Agradezco a la autora el haberme dejado consultar su Tesis Doctoral todavía inédita).

13 Royo J.I. et alii: «Excavaciones en La Malena (Azuara, Zaragoza) $3^{a}$ campaña 1988», Arqueología Aragonesa 1988-89, 1991, págs. 209- 221; FERNÁNDEZ GALIANO D.: «Cadmo y Harmonía: imagen, mito y arqueología», Journal of Roman Archaeology 5, 1992, págs. 162- 177. 


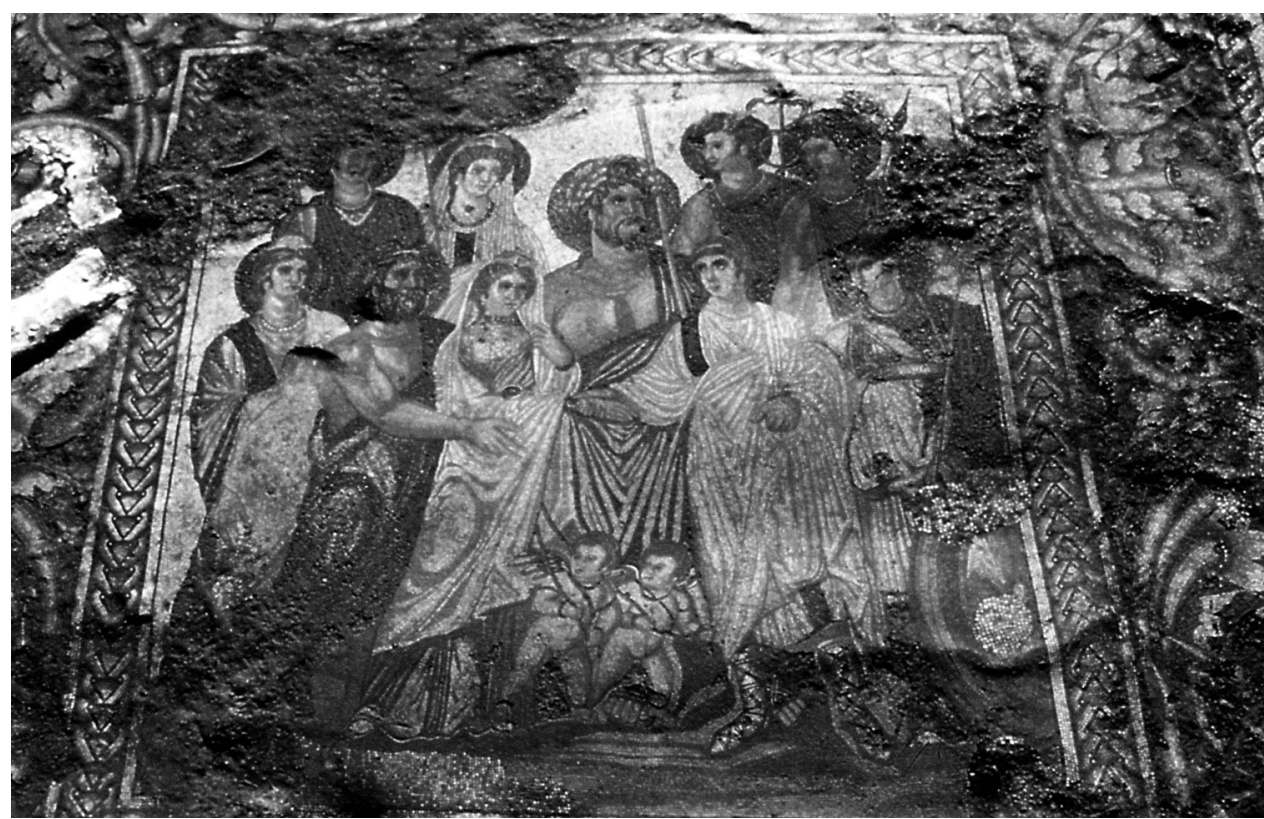

Fig. 4- Mosaico de las Bodas de Cadmo y Harmonia de la Villa de La Malena, Azuara (Zaragoza). Siglo IV- $V$.

\section{Venus marina}

El episodio mitológico del Nacimiento de la diosa o navegando en su concha aparece en tres mosaicos hispanos, Cártama (Málaga) fechado a finales del siglo $\|^{14}$ (Fig. 5), Itálica de principios del siglo $\|^{15}$ y en la Quintilla (Murcia) del siglo IV ${ }^{16}$. En los mosaicos de Cártama y la Quintilla Venus aparece reclinada en la concha, tipo similar al representado en las pinturas y mosaicos parietales del siglo I de Pompeya, aunque en los ejemplares hispanos la concha tiene un mayor protagonismo. Todo ello estaría en relación con el célebre dato de Plauto (Rud. 704) y otros autores posteriores de recalcar que «Venus nació de una concha», al igual que los delfines bajo la concha, animal asociado a Afrodita marina que sugiere felicidad y bienaventuranza, subrayarían la prosperidad del viaje, destacándose en estos casos hispanos la gran concha en la que navega Venus que algunos autores mencionan como una especie de bajel. En los pavimentos de Itálica y de Quinta-

14 BlázQueZ, J.M.: op. cit. en nota 4, págs. 85- 88, láms. 70- 71.

15 CANTO, A.: «El mosaico del Nacimiento de Venus en Itálica», Habis 7,1976, págs. 293- 338, láms. XV- XVIII.

16 BLÁzQUeZ, J.M.: Mosaicos romanos de Sevilla, Granada, Cádiz y Murcia, CMRE IV, Madrid 1982, págs. 62- 63, fig. 21; Ramallo, J.F.: Mosaicos romanos de Carthago Nova (Hispania Citerior), Murcia 1985, pág. 95; RAMALLO, J.F. et alii: «La villa romana de la Quintilla (Lorca, Murcia): análisis de su programa decorativo y ornamental», La Mosaïque Greco-Romaine IX, Roma 2005, págs. 1008-1009. 


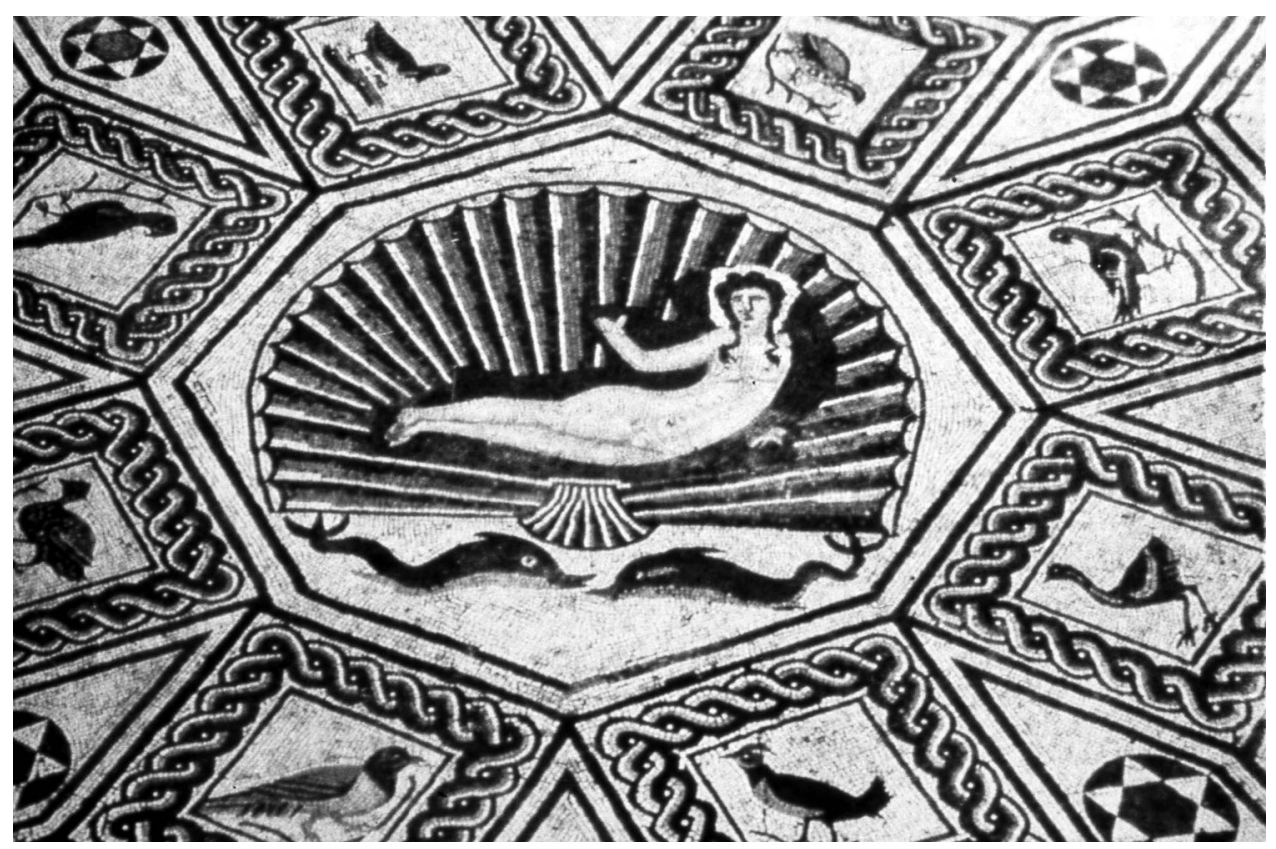

Fig. 5- Mosaico del Nacimiento de Venus de Cártama (Málaga). Finales del siglo ॥

nilla dos tritones sostienen la concha, iconografía que aparece igualmente en la musivaria bícroma de Italia, siglo II, y en la producción norteafricana y oriental con el Triunfo y la «Toilette» de Venus ${ }^{17}$.

\section{Tethys}

Esta diosa hermana y paredro de Océano, aparece en dos mosaicos hispanos, probablemente saliendo del mar como la describe Homero (IL. 1.357 ss). Un ejemplar en la villa de Bruñel, Jaén, de la segunda mitad del siglo III o principios del IV ${ }^{18} \mathrm{y}$ otro en Marroquíes Altos, Jaén de la segunda mitad del siglo IV ${ }^{19}$ (Fig. 6). Este último mosaico es la representación que tiene más atributos. En el cuello de Tethys, a modo de collar, se enrosca un pez serpentiforme, lleva un ala en la parte posterior de la cabeza y patas de cangrejo en los dos lados de la cabeza. Está situada entre dos kethoi que la miran. A su izquierda figura un remo. Delfines, peces

17 Véase todos los paralelos musivos en SAN Nicolás PEDRAZ, M.P.: «La iconografía de Venus en los mosaicos hispanos", VI Coloquio Internacional sobre Mosaico Antiguo (Palencia- Mérida 1990), Mérida 1994, págs. 393- 394, notas 4, 8- 10.

18 BLÁZqueZ, J.M.: op.cit. en nota 4, pág. 64, n. 43, lám. 52; FERnÁNDEZ GaliANO, D.: «Nuevas interpretaciones iconográficas a mosaicos hispanos», Museos I , 1982, pág. 17.

19 BlázQueZ, J.M.: op. cit. nota 4, págs. 59- 60, nº 37, láms. 44-45. 
y una concha rodean a la diosa. La iconografía de Tethys sola y en busto aparece en varios mosaicos de los siglos III y IV, hallados principalmente en la parte oriental del Imperio, en Antioquia y Siria (Shahba Philippopolis) ${ }^{20}$. Los atributos de los kethoi, el remo y el contexto marino de peces son los habituales. El atributo de las patas de cangrejo que lleva en la cabeza, no aparece en ningún ejemplar de la serie, pues son más propias de Océano y de Thalassa. Esta última personificación femenina del mar también aparece en la musivaria oriental con la misma iconografía que Thetys, en busto, sola o con Océano, remo, monstruos marinos, delfines y otros peces como en los pavimentos de Jordania y Armenia, así como los de Libia, fechados entre los siglos II al VI, aunque suele llevar su nombre en griego para su identificación ${ }^{21}$. Por lo tanto existe una interrelación iconográfica entre ambos personajes, aquí estaría representada Thetys o Thalassa (?).

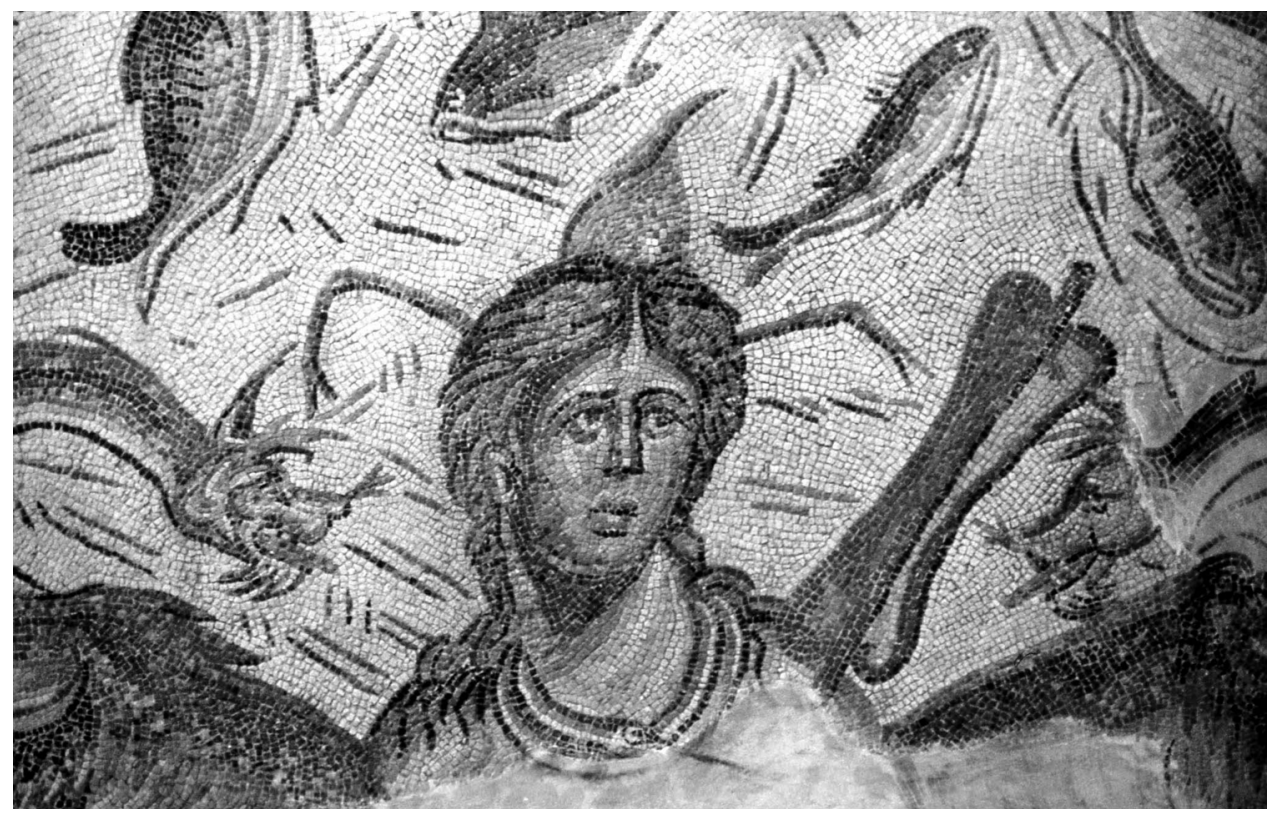

Fig. 6- Mosaico de Tethys de Marroquies Alto (Jaén). Segunda mitad del siglo IV.

La diosa Tethys podría estar representada en el mosaico Cogmológico de la Casa del Mitreo, en Augusta Emerita, de profundo simbolismo filosófico y fechado en la segunda mitad del siglo $\Perp^{22}$. En este gran pavimento Tethys estaría situada en

20 LIMC VIII, «Thetys I», $\mathrm{n}^{\circ} .7-14$.

21 LIMC VIII, «Oceanus», $\mathrm{n}^{\circ}$ 53; LIMC VIII, «Thalassa», $\mathrm{n}^{\circ} 11-14$

22 Blanco A.: op. cit. en nota 6, pág. 38, fig. 1, láms. 36-37; QUET, M.H.: La mosaïque cosmologique de Mérida, 1981; BLÁzQUeZ, J.M.: “Cosmología mitraica en un mosaico de Augusta Emérita», AEspA 59, 1986, págs. 89- 100; FERNÁNDEZ GALIANO, D.: «Observaciones sobre el mosaico de Mérida con la Eternidad y el Cosmos», Anas 2/3, 1989-1990, págs. 173- 182. 
el lado derecho, en una zona muy estropeada, y en contraposición a la figura de Océano, y probablemente figuraría de cuerpo entero y sentada como su paredro. ${ }^{23}$. Esta iconografía de la diosa no es tampoco desconocida en los mosaicos romanos, la encontramos tanto sola (mosaicos de Antakya, del siglo III o principios del IV, y Tartous del siglo III) como con Océano (mosaicos de la Casa del Calendario, fechado en los comienzos del siglo II, y de la Casa de Océano y Tethys, del siglo III, en Antioquia, así como en Zeugma) ${ }^{24}$.

\section{Tritones}

Existen veintiún mosaicos con estas representaciones. Son figuras con el cuerpo humano de tres cuartos, generalmente jóvenes e imberbes, y con cola de pez, a veces doble (Santa Vitória do Ameixial) ${ }^{25}$ según relatan algunos autores como Ovidio (Heroid. XII, 49) y Nonnos (Dion. XXXV, 94), o con las patas anteriores equinas (Milreu ${ }^{26}$ en Portugal e Itálica) (Fig. 7), icthiocentauros, (Barcino ${ }^{27}$, Augusta Emerita ${ }^{28}$, Casariche ${ }^{29}$, calle de Pescadores de Itálica ${ }^{30}$, Santa Vitória do Ameixial, El Chorreadero en Cádiz ${ }^{31}$, La Cocosa en Badajoz ${ }^{32}$, Conimbriga ${ }^{33}$ )

23 Torres Carro, M.: op. cit. en nota 5, pág. 131, nota 132.

24 Véase estos ejemplares en LópeZ Monteagudo, G.: op. cit. en nota 4; BlÁzQueZ, J.M. et alii: «Representaciones mitológicas, leyendas de héroes y retratos de escritores en los mosaicos de época imperial en Siria, Fenicia, Palestina, Arabia, Chipre, Grecia y Asía Menor», Antigüedad y Cristianismo (Murcia), 2004, pág. 296, fig. 12.

25 TORRES CARRO, M.: «La escena de Ulises y las sirenas del mosaico de Santa Vitória», BSAA XLIV, 1978, págs. 89- 102; NEIRA, M.L.: «Acerca de las representaciones del thiasos marino en los mosaicos romanos tardoantiguos de Hispania», Ant.Crist. VIII, 1991, págs. 516- 524, figs. 7- 8.

26 Almeida, F. de: Arte visigótica em Portugal. O Arqueólogo portugues, Lisboa 1962, Sér. II,4, pág. 233, lám. 53; SoARES dos SANTOS, A.R (coord.).: Mosaicos romanos. Nas Colecçoes do Museu Nacional de Arqueologia, Lisboa 2005, pág. 26; FEICHNER, F: «De lo romano a lo árabe. La transición del sur de la provincia de lusitania a Al- Gharb Al- Andalus. Nuevas investigaciones en los yacimientos de Milreu y Cerro de Vila», Anejos de AEspA XXXIX, 2006, págs. 213-214, fig. 8.

27 BALIL, A.: «El mosaico romano de la iglesia de San Miguel», Cuadernos de Arq. e Historia de la Ciudad I, 1960, 21- 74; BARRAL, X.: op. cit. en nota 9, págs. 39- 43, nº 7, láms. XII- XIV.

${ }_{28}$ Garcia Sandobal, E.: «Informe sobre las casas romanas de Mérida y excavaciones en la Casa del Anfiteatro», $E A E$ 49, 1966, pág. 8, láms V- VIII; BLANCO, A.: op. cit. en nota 6, págs. 29- 30, n. 7, láms. 8-10.

29 Mondelo, R. y Torres Carrro, M.: op. cit en nota 4, págs. 143- 155, láms. I-II.

30 Blanco, A.: Mosaicos romanos de Itálica, CMRE I, Madrid 1978, págs. 32- 34, nº 8, láms. 20-27; NEIRA, M.L.: «El mosaico de los tritones de Itálica en el contexto iconográfico del thiasos marino en Hispania», VI Coloquio Internacional sobre Mosaico Antiguo (Palencia- Mérida 1990), Mérida 1994, págs. 359-367.

${ }^{31}$ Corzo, R.: «Un nuevo mosaico romano de thiasos marino», BMusCád III, 1981-82, págs. 51- 54. BLÁZQUEZ, J.M.: op. cit. en nota 16, págs. 52-53, n. 48-49, láms. 15, 20-21.

32 Alvarez, J.M.: «El mosaico del tritón de la villa romana de La Cocosa (Badajoz)», Homenaje al Prof. Martín Almagro Basch III, Madrid 1983, págs. 379- 388, láms. I- II; NEIRA, M.L.: op. cit. en nota 25, págs. 516, 519- 520 y 524, lám. 5 .

${ }_{33}$ BairRao Oleiro, J.M.: «Mosaïques romaines du Portugal», CMGR I, Paris 1965, págs. 257, 260263, fig. 5 ; AlARÇAO, DE J.: Portugal romano, Lisboa, «Historia Mundi» Verbo, 1974, pág. 194 ; BLÁZQUEZ, J.M. et alii: «La mitología en los mosaicos hispano- romanos», AEspA 59, 1986, pág. 129, fig. 46; LóPEZ Monteagudo, G.: op. cit en nota 3; Bairrao Oleiro, J.M.: Conimbriga. Casa dos Repuxos. Corpus dos Mosaicos Romanos de Portugal, Conímbriga 1992, págs. 84-87. 


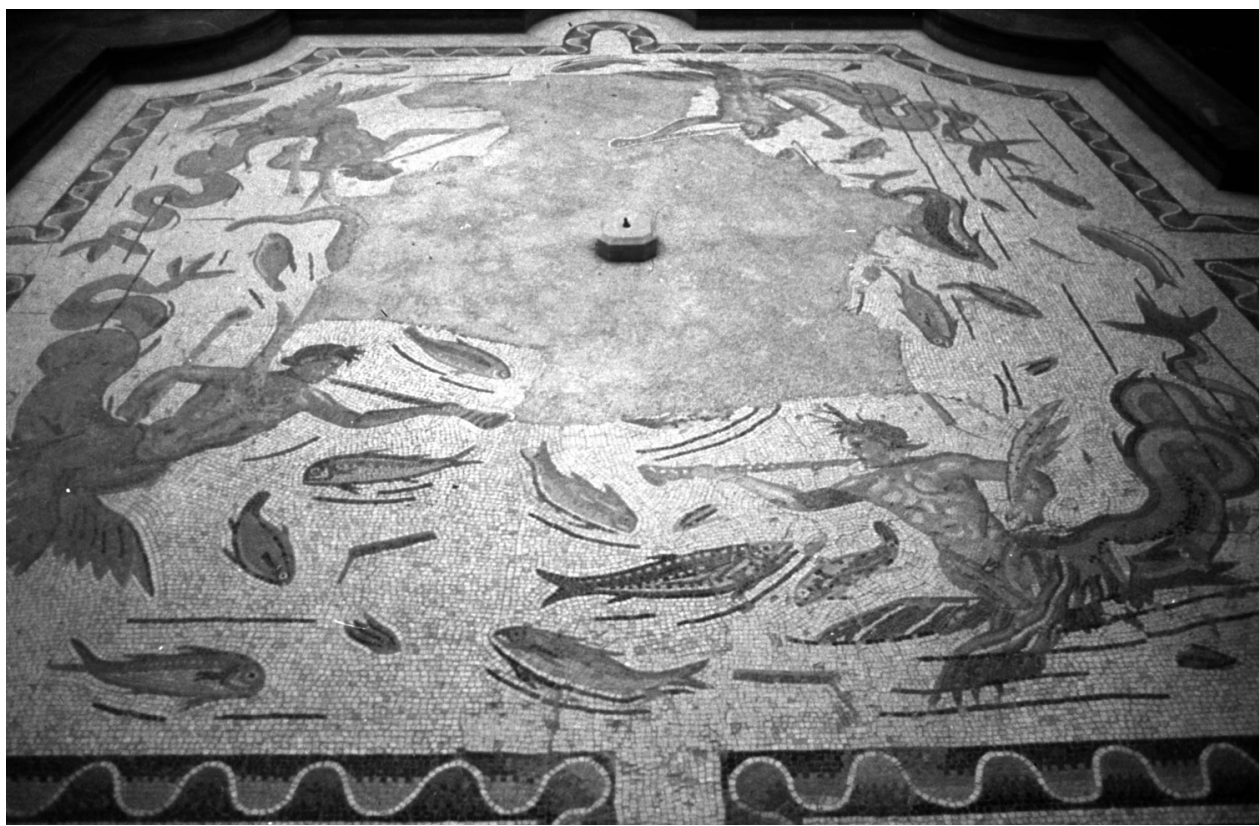

Fig. 7- Mosaico de Tritones de Itálica. Comienzos del siglo III.

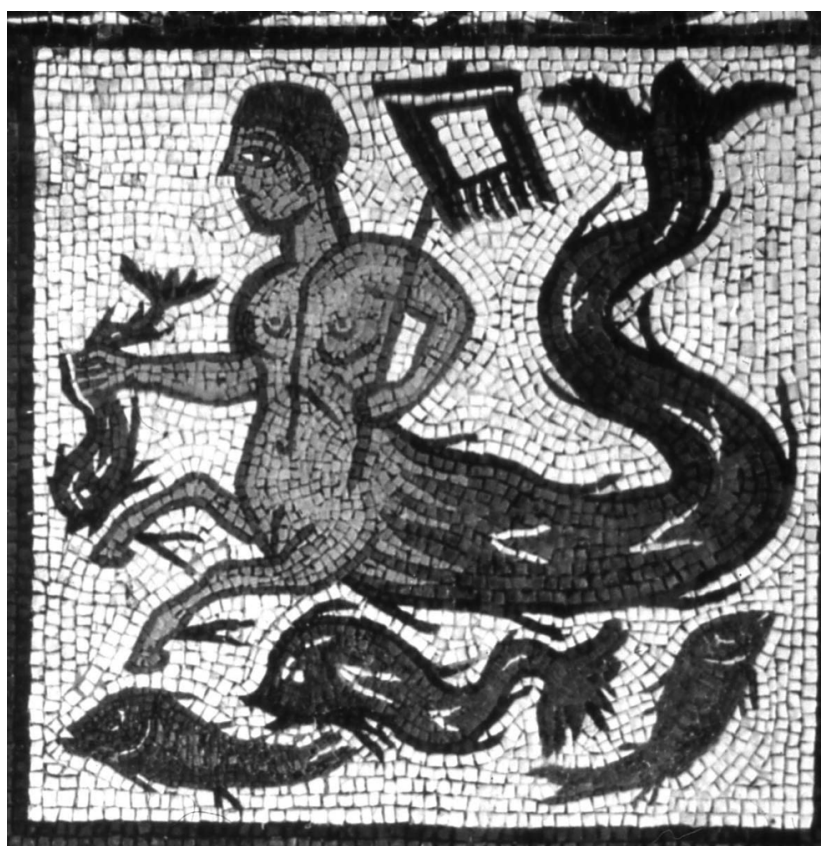

Fig. 8- Mosaico de Tritón de Conimbriga (Portugal). Finales del siglo II- principios del III. 
(Fig. 8), o en forma de aletas (calle de los Pescadores de Itálica y Casariche). Sus atributos son variables, la buccina es el más frecuente, el remo la caracola, el delfín, el pedum. En cuanto a la composición existen diferentes esquemas, ya sean protagonistas del mismo cortejo (pav. de Barcino, La Cocosa ${ }^{34}$, un panel de Santa Vitória y Sasamón en Burgos aquí aparece en busto, con dos pinzas de cangrejo en la cabeza y aislado del thiasos, en el octogono central) $)^{35}$, miembros de un thiasos como los de Neptuno (Itálica y Augusta Emerita ya citados) o acompañando a otras figuras, Venus marina (Nacimiento de Venus de Itálica y La Quintilla, supra), Océano (Córdoba ${ }^{36}$ y Casariche, en este último los tritones aparecen en otros compartimentos), Gorgona (pav. de Canama en Alcolea del Río, Sevilla, los tritones estaban dispuestos alrededor de la Gorgona) ${ }^{37}$, auriga victorioso (EI Pomar en Jerez de los Caballeros, Badajoz) ${ }^{38}$, con un delfín y otros animales fantásticos (Ampurias) ${ }^{39}$ una nave como el mosaico del tritón de Fuente Alamo, Córdoba) (acompañado también de un caballo marino y de varias figuras muy deterioradas) $u$ otro motivo desconocido por la destrucción (Santa Vitória y fragmentos de Santiponce en Itálica $\left.{ }^{40}\right)$.

\section{Nereidas}

La figura de las nereidas en la musivaria romana de Hispania es menos frecuente que la de los tritones, aparecen en diez mosaicos. Las encontramos, al igual que ellos, formando parte del thiasos de Neptuno (Augusta Emerita), de Océano (Dueñas, Palencia, en donde aparecen dos nereidad, situadas a ambos lados del dios, una sentada sobre un toro marino y la otra sobre una pantera $)^{41}$ (Fig. 9), las dos nereidas del mosaico muy fragmentado hallado en las termas pri-

34 SerRA y RÀfols, J. de C.: La villa romana de La Cocosa, Badajoz, 1952, págs. $79-82$

35 AbÁsolo, J.A. y García, R.: Excavaciones en Sasamón (Burgos), EAE 164, Madrid 1993, págs. 179- 192, fig. 95, láms. XIX- XXVI; LóPEZ MonTEAGUdo, G. et alii: Mosaicos romanos de Burgos CMRE XII, Madrid 1998, pág. 32, n. 159, fig. 8, láms. 19-20 y 44.

${ }^{36}$ Marcos Pous, A. y Vicent Zaragoza, A.M.: «Investigació, técnicas y problemas de las excavaciones en solares de la ciudad de Córdoba y algunos resultados topográficos generales», Arqueología de las ciudades modernas superpuestas a las antiguas. Ministerio de Cultura, Madrid 1985, pág. 244 y fig.; LóPEZ MonTEAgudo, G.: (2006), op. cit. en nota 4, págs. 499- 500.

37 Campos, M.: Mosaico del Museo Arqueológico provincial de Sevilla, Sevilla 1896 pág. 16; NEIRA, M.L.: op. cit. en nota 29, pág. 366NeIRA, M.L.: «Paralelos en la musivaria romana de Grecia e Hispania. A propósito de un mosaico de Alcolea del Río y un pavimento de Mitilene», Anales de Arqueología cordobesa 9, 1998, págs. 223- 246.

38 Alvarez, J.M.: «El mosaico de la villa romana de El Pomar (Jerez de los Caballeros)», Homenaje al Prof. D. A. Blanco (1989), págs. 341-351, láms. 74-82; NEIRA, M.L.: op. cit. en nota 25, pág. 514 , fig. 1.

39 AquíLUÉ, $\mathrm{X}$, et alii: «Primers resultats del project d'intervenció arqueológica a les termes publiques de la ciutat romana d’Emporiae (Empúries, L’Escala, Alt Empordà)», Empúries 53, 2002, págs. 247- 249, figs. 7-8.

40 Campos, M.: op. cit. en nota 36, págs. 14-17 ; Torres Carro, M.: op. cit. en nota 5, págs. 110- 112, 123- 124; NeIRA, M.L.: op. cit. en nota 25, pág. 366.

41 Palol, P.: «El mosaico de la villa de Dueñas (prov. Palencia)», BSAA XXIX, 1963, págs. 1- 30; Id., «Das Okeanus-mosaik in der römischen villa zu Dueñas (Palencia)», Madrider Mitteilungen 8, 1967, págs. 196- 230. NeIRA, M.L.: op. cit. en nota 25, págs. 516, 520-521, 524, fig. 6 
vadas de una domus descubierta recientemente en Écija ${ }^{42}$, o de otro personaje actualmente indeterminado por su destrucción (Santa Vitória). También aparece con Eros navegando sobre un ánfora (Carmona) ${ }^{43}$, con Eros y Psique (pav. perdido de Itálica,) ${ }^{44}$, con Polifemo (mosaico de Polifemo y Galatea de Córdoba) ${ }^{45}$, aislada (Dehesa del Hinojal, está representada recostada sobre un kethos) ${ }^{46}$. A veces están identificadas por una inscripción con su nombre como ocurre con Galatea en el pavimento de Galatea en Algorós, Elche (la figura se encuentra sentada sobre un hipocampo, con la particularidad que está nimbada resaltando su carácter divino) ${ }^{47}$; inscripciones con su nombre aparecen igualmente en los mosaicos de Antioquía

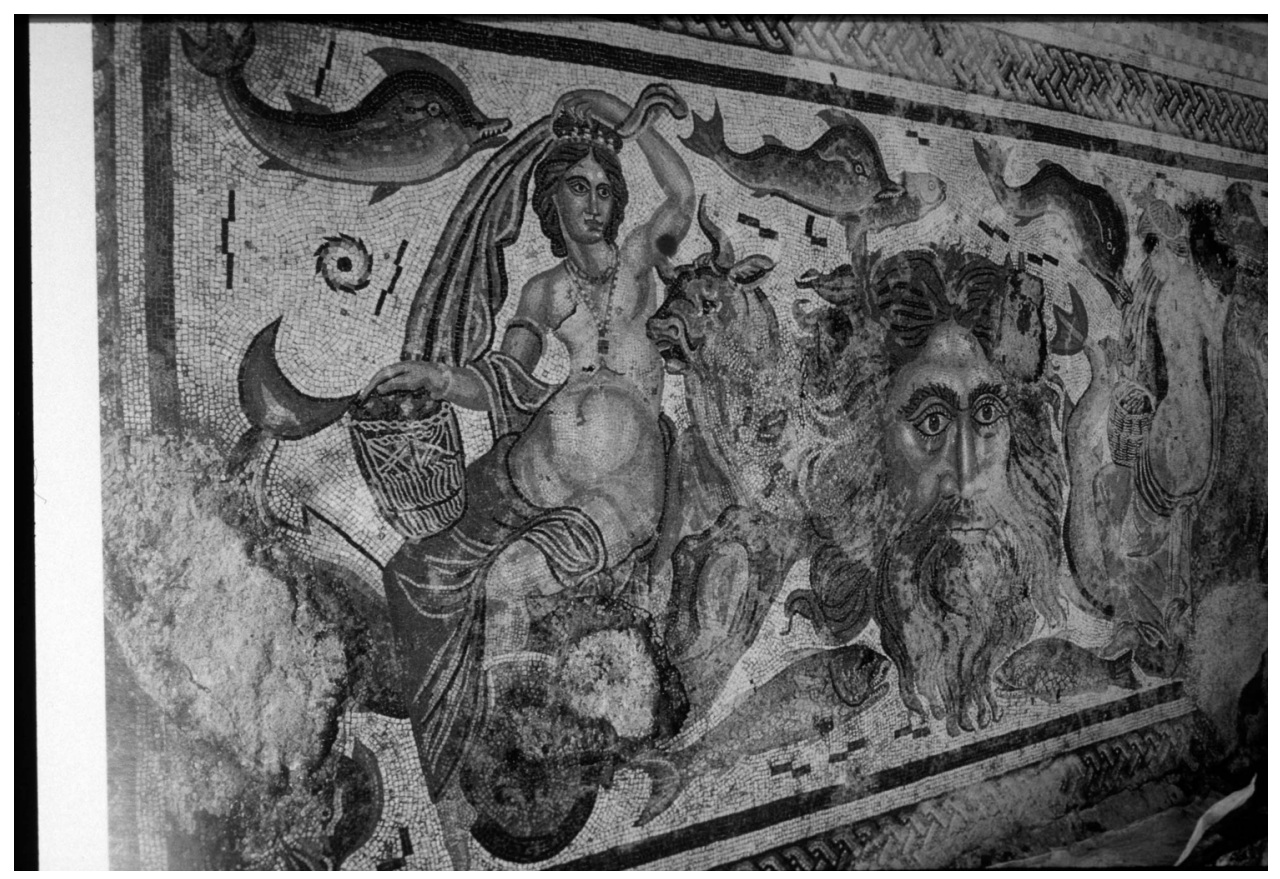

Fig. 9- Mosaico de Océano de la Villa de Dueñas (Palencia). Siglo IV.

42 GarcíA- Dils, S. et alii: «Mosaicos romanos de Écija (Sevilla). Nuevos hallazgos», $X^{\circ}$ Coloquio Internacional/Aiema. O Mosaico Antigonos centros e nos periferias: originalidades, influencias e identidades (Conimbriga, Portugal 2005), en prensa.

43 CaRTAya Baños, J.: «Mosaicos romanos de Carmona», en A Ceballos (ed.), Carmona romana, Carmona 2001, págs. 293- 309, figs. 16 y 18.

44 Celestino, S.: «Mosaicos perdidos de Itálica», Habis 8, 1977, págs. 366- 370, lám. XXVI; NEIRA, M.L.: op. cit. en nota 25, pág. 517, nota 29.

45 BlázQueZ, J.M.: op. cit en nota 4, págs. 13- 17, nº 1, fig. 1-2, láms. 1-2, 81.

46 AlvareZ, J.M.: «La villa romana de El Hinojal en la Dehesa de las Tiendas (Mérida)», NotArqHisp. IV, 1976, págs. 450-451, 456-457, 462-463, fig. 3, láms. XI-XII; BLANCO, A.: op. cit. en nota 6, pág. 51, nº. 63, láms. 93b-94a; NeIRA, M.L.: op. cit. en nota 25, págs. 515- 524, fig. 4.

47 Mondelo, R.: «Los mosaicos de la villa romana de Algorós (Elche)», BSAA LI, 1985, págs. 107141; BLÁzQUEZ, J.M. et alii: Mosaicos romanos del Museo Arqueológico Nacional, CMRE IX, Madrid 1989, págs. 35- 37, n. 17, fig. 17, láms. 18 y 40; NEIRA, M.L.: op.cit. en nota 25, págs. 515- 516 y 520- 524, figs. 3 y 9 . 
y Chipre ${ }^{48}$. También pueden estar identificadas por el contexto así ocurre con Galatea en el citado mosaico de Córdoba en donde aparece conversando con Polifemo, tema usual en las pinturas pompeyanas, mosaicos de Antioquía y Norte de Africa, así como en sarcófagos ${ }^{49}$.Igualmente la nereida Thetis aparece en el mosaico de Aquiles y Pentesilea de Complutum por su relación con el héroe, al ser su madre ${ }^{50}$.

\section{Animales fantásticos}

En este grupo hemos agrupado aquellos animales que como los hipocampos ${ }^{51}$ presentan la mitad posterior de su cuerpo en forma de animal marino (kethoi, toros, ciervos, cabras, felinos...). Existen veintiún mosaicos. Pueden estar en solitario (Sasamón, con el tritón ya citado en el centro (Fig. 10); Pompaelo?52; Ciella,

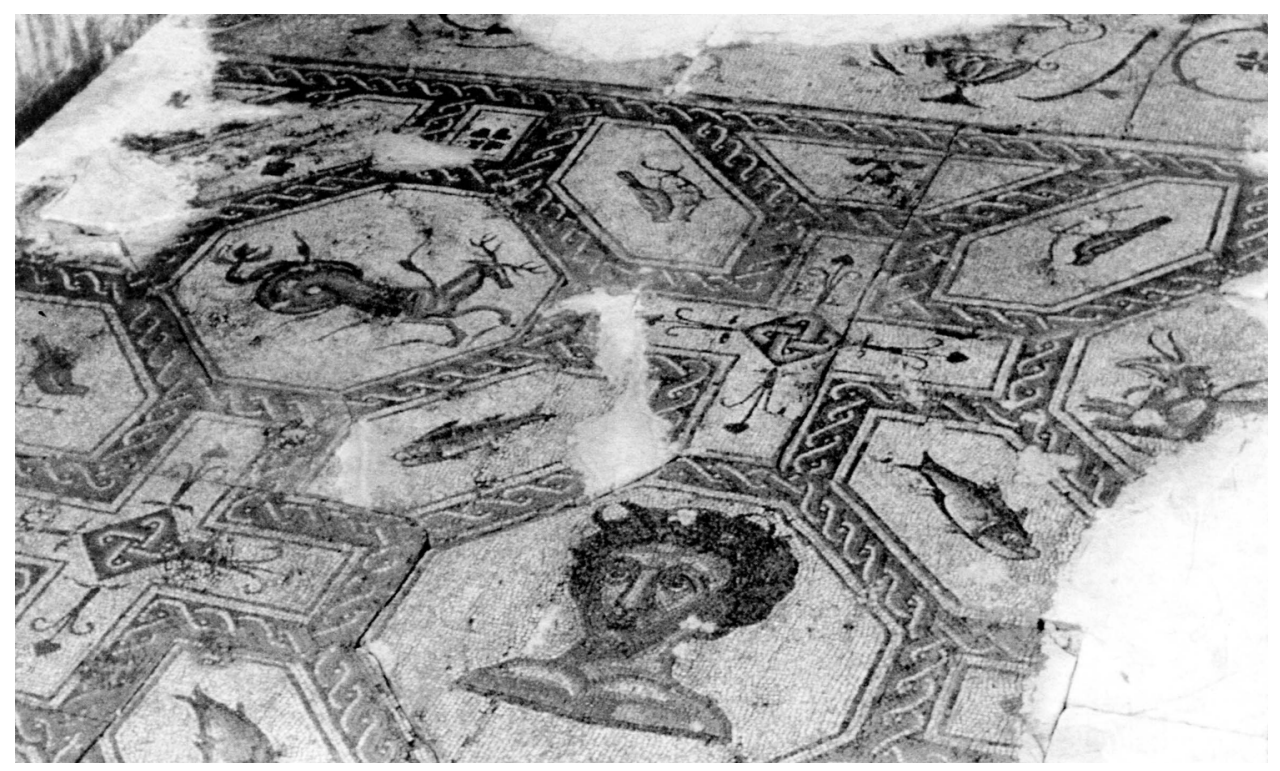

Fig. 10- Mosaico con Tritón y animales fantásticos Sasamón (Burgos).

Finales del siglo II-comienzos del III.

\footnotetext{
48 NeIRA, M.L.: op. cit. en nota 25, pág. 523 notas 45 y 46.

49 Torres Carro, M.: op. cit.en nota 5, pág. 126, notas 105- 108.

50 Fernández Galiano, D.: Complutum. II Mosaicos, EAE 138, Madrid 1984, págs. 60- 61, láms. XXXI

51 Para A. BALIL estas imágenes fantásticas tendrían su origen en los vasos áticos de figuras negras entre otros, cf. «El mosaico romano de la Iglesia de San Miguel», Cuadernos de Arq. e Hist. de la Ciudad 1,1960, págs. 21-24.

52 BLÄZQUeZ, J.M. y MeZquIRIZ, M.A.: Mosaicos romanos de Navarra, CMRE VII, Madrid 1985, págs. 55- 56, $n^{\circ}$. 35, lám. 34. SAN Nicolás PedRaz, M.P.: «Mosaicos hispano- romanos con representaciones de murallas", L'Africa Romana XV, 2004, pág. 833, fig. 11.
} y L. 
Burgos ?53; finca de Don R. Irles cerca de La Alcudia de Elche ${ }^{54}$; Portugal, de procedencia desconocida ${ }^{55}$ ) o formando parte de un thiasos marino $u$ otras figuras (Barcino; dos en Córdoba, uno en la misma ciudad y el otro a $3 \mathrm{~km}$. de ésta ${ }^{56}$; Conimbriga; Augusta Emerita; Illici ${ }^{57}$, Carranque ${ }^{58}$, Casariche y Madrigalejo en Cáceres ${ }^{59}$, todos ellos con Océano; Itálica con Neptuno; mosaico de la calle de Pescadores de Itálica, con tritones y peces; Ampurias con un tritón y un delfín; Marroquíes Alto, Jaén, con Tethys; Córdoba, con Galatea y Polifemo; Conimbriga, Kethos y Perseo ${ }^{60}$; Tarragona, con Perseo y Andrómeda ${ }^{61}$; Fuente Álamo, Córdoba, con nave, tritón y varias figuras).

\section{Daimones}

Un unicum en la musivaria romana lo constituye la cabeza que emerge del agua, con abundante cabellera, orejas leoninas y quizás una serpiente al cuello en

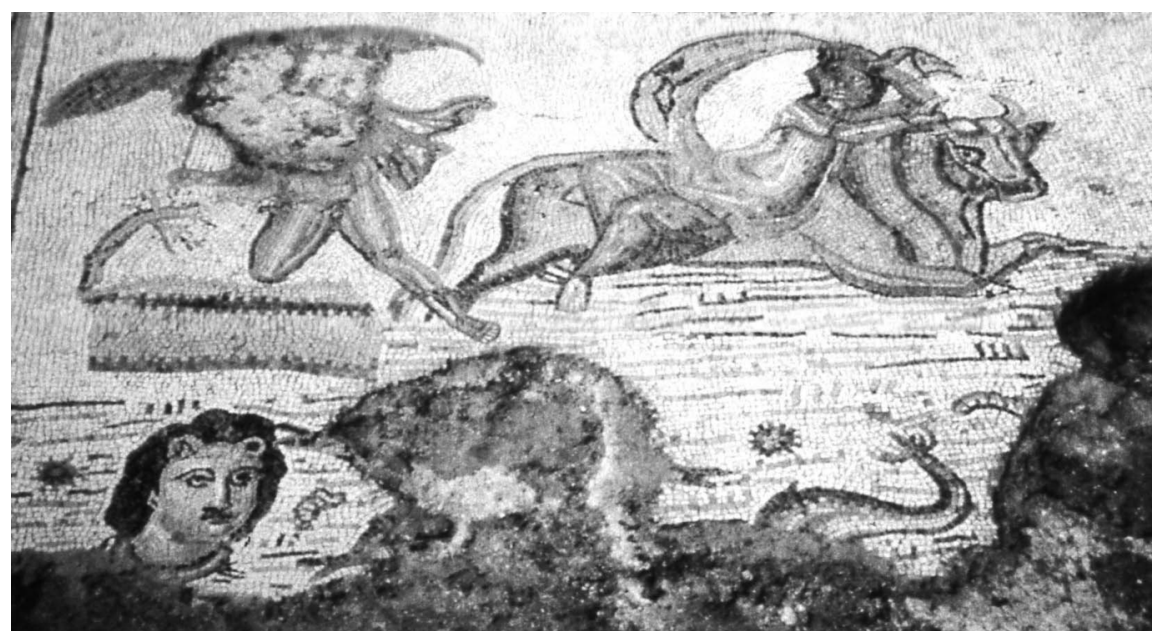

Fig. 11- Mosaico de los Amores de Zeus de la Colonia Augusta Firma Astigi. Siglo II-III.

53 LÓPEZ MonTEAgudo, G. et alii : op. cit. en nota 34, pág. 38, nº 17, láms. 21 y 45.

${ }^{54}$ Ramos Folqués, A. (1970): Historia de Elche. Elche, pág. 56; RuIz, E. (2001): Los mosaicos de Illici y del Portus Illicitanus, Valencia, pág. 48, fig. 8.

55 Soares dos Santos, A.R (coord.).: op. cit. en nota 26, pág. 22.

${ }^{56}$ BLÁZQUeZ, J.M.: op. cit. en nota 4, pág. 19, nº. 4, láms. 3- 7, láms. 3- 6; pág. 48, n゚. 28, láms. 37- 38.

57 Albert, J.: «Descubrimiento de un mosaico en Elche», AEspA 18, 1945, págs. 340- 342. RAmOS FolquÉs, A. (1970), op. cit. en nota 49, págs. 55-56; RuIz, E. (2001), op. cit. en nota 49, págs. 45-49.

58 Fernández-GaliANo, D.: «Mosaicos de la villa de Carranque: un programa iconográfico», VI Coloquio Internacional sobre mosaico antiguo (Palencia-Mérida 1990), Palencia 1994, pág. 324, fig. 6; LóPEZ MonteAGudo, G. (2006), op. cit. en nota 4, págs. 501- 502; LóPEZ MonteAGUdo, G. (en prensa).

59 BRAH 10, 1887, págs. 165-168; MÉLIDA, J.R. Catálogo monumental de España. Provincia de Cáceres (1914- 1916), Madrid 1924, págs. 178- 179.

60 LóPez Monteagudo, G.: (1990) op. cit. en nota 2, págs. 203-204, fig. 3; BairRao Oleiro, J.M.: (1992), op. cit. en nota 32, págs. 32- 36, fig. 26; LóPEZ MONTEAGUDO, G.: (1998a) op. cit. en nota 4, pág. 454- 455, fig. 14.

${ }^{61}$ LóPez Monteagudo, G.: (1998a) op. cit. en nota 4, pág. 462- 467, fig. 22. 
el mosaico de los raptos de Europa ${ }^{62}$ y Ganímedes, hallado en una casa de la CoIonia Augusta Firma Astigi del siglo II- III, que se ha identificado con un daimon que, junto a las nereidas, hipocampos, delfines y otros seres pueblan el mar como intermediarios de la vida y la muerte ${ }^{63}$ (Fig. 11).

\section{FIGURAS ALEGORICAS}

\section{Ríos}

Se trata de figuras de hombres maduros, barbados y de aspecto venerable, y aparecen aisladas o formando una composición. A veces suelen estar acompañadas por la inscripción con su nombre, otras veces llevan algún atributo específico que les identifican como el cuerno de Aqueloo o los putti, hipopótamo, cocodrilo del Nilo. En Hispania existen ocho mosaicos en los que se identifican seis ríos diferentes (Asopo, Aqueloo, Éufrates, Nilo, Orontes, Pyramo) y forman parte de una historia excepto el pav. de Fuente Álamo con el río Nilo y el de la Casa del Planetario de Itálica, en este último es un río no identificado.

El mosaico perdido de Fernán Nuñez, Córdoba, de finales del siglo $1 I^{64}$ y en uno de los medallones de Itálica, fechado a finales del siglo II o comienzo del III65, reflejan una secuencia anterior y otra posterior del episodio del rapto de Egina, hija de Asopo, por Zeus, poco usual en las obras artísticas romanas ${ }^{66}$. En el primer mosaico el dios- río Asopo, junto a Egina y la madre de está, la ninfa Metope, aparece de espaldas al espectador, iconografía poco habitual de las divinidades fluviales, reclinado y apoyado en un cántaro de donde cae agua. En el otro pavimento figura reclinado sobre una roca con el cuerno de la abundancia como símbolo de la fertilidad que aporta el río y con una rama con la que toca una roca con árbol, que indicaría el momento de hacer brotar la fuente Pirene en la ciudad de Corinto, con la que el dios compra a Sísipo la información sobre el raptor de su hija (Apod. Bibli., III, 12,6; Diod., IV, 72).

Aqueloo figura en dos mosaicos de la Bética, en el pavimento de Osuna, Sevilla, hoy perdido, de la segunda mitad del siglo III, del que se conoce por una des-

62 López Monteagudo, G. y San Nicolás Pedraz, M.P.: «El mito de Europa en los mosaicos hispanoromanos. Analisis iconográfico e interpretativo", Espacio, Tiempo y Forma II/8, 1995, págs. 420-423, fig. 36; LóPEZ MonTEAGUdo, G.: «Los mosaicos romanos de Ecija (Sevilla). Particularidades iconográficas y estilísticas», CMGR VIII, Túnez, Institut Nacional du Patrimone, 2001, págs. 132- 134, lám. IV.

${ }^{63}$ LÓPEZ MONTEAGUDO, G.: «El simbolismo de la travesía marina en algunos mitos clásicos», Latomus 57/1 1998, págs. 38-51. En un trabajo reciente la autora opina que podría tratarse de una herma báquica cf. LóPEZ MONTEAGUDO, G.: «Lo provincial y lo original en los mosaicos romanos. Original versus provincial», en Homenaje a la profesora Pilar León Alonso, Córdoba 2006, pág. 285.

${ }^{64}$ Fernández Galiano, D.: op. cit. en nota 18, pág. 19, fig. 1.

65 MANJón, R.: «El mejor mosaico de Itálica», Boletín de la Real Academia de la Historia 67, 1915, págs. 235- 242; BLANCO, A.: op. cit. en. nota 28, págs. 25- 26; FeRnÁndEZ GALIANO, D.: op. cit. en nota 18, pág. 19.

66 LIMC II s. v. «Asopos». 
cripción ${ }^{67}$ y en el mosaico de Los trabajos de Hércules de Cártama, Málaga, de principios del siglo III68. En el primero aparecía, en el centro, el río sentado en el suelo y apoyado en una urna, llevando en la frente un solo cuerno e identificado con la inscripción $\mathrm{ACHE}$ (lous), mientras que en los ángulos estaban representadas cuatro bustos femeninos, algunos con sus nombres, SIRE(ne), NYMPHE, posiblemente Amaltea, además de Terpsícore (madre de las Sirenas según algunos

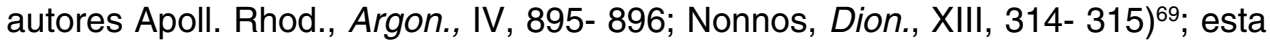
iconografía de Aqueloo con sus hijas las sirenas es un unicum en la musivaria romana. En el segundo el dios aparece dentro de uno de los recuadros del mosaico, con el pelo desordenado, sentado sobre un promotorio rocoso, con la frente sobre el brazo, en actitud pensativo y triste, como derrotado, a su espalda aparece unos arbustos acuáticos haciendo referencia a su carácter fluvial. En esta escena Aqueloo no lleva en la frente el cuerno indicando que ha sido ya arrebatado por Hércules para Eneo, por la mano de su hija Deyanira según la conocida leyenda (Paus. III18,6; Hom. II., XXI 194; Sof. Trach. 6 ss. y 540 ss.; Estrab., X,4-58; Filostr., lum, mi.4; Diod., IV,35; Ovd., Met., VIII, 21, entre otros); esta derrota del dios está de acorde con las otras escenas del mosaico en donde se representan al héroe ya vencedor y no en lucha contra sus enemigos, con un sentido alegórico a la idea de virtus sobre el mal. El paralelo iconográfico más exacto para este pavimento hispano se encuentra en un ejemplar de Acholla (Túnez), del año 184, hallado en una mansión del cónsul Asinio Rufo, que según Gozlan respondería a un modelo pictórico ${ }^{70}$.

En el gran mosaico Cosmológico de Mérida, ya citado, aparecen varias personificaciones del mundo acuático identificadas con su nombre en latín (Fig. 12). El río Éufrates figura sentado y apoyando su brazo izquierdo en una urna y con la otra mano sostiene un tallo de rosa. A su izquierda, sentado, está el Nilo que tiene a sus pies un niño con proa, mástil y velamen; esta figura de puttus o «codo» indica la fertilidad del río, como aparecía en las pinturas descritas por los autores antiguos (Pilostr. , Mi., I,5; Luc. Rhetorum praecep., 6$)^{71}$ y sus aguas tenían grandes cualidades curativas y eran fértiles para las mujeres estériles ${ }^{72}$. También aparece el río Orontes como un bañista sumergido, con el agua hasta el pecho, tendiendo sus

67 Thouvenot, R.: Essai sur la province romaine de Bétique, Paris 1940, págs. 645- 646, (reimp. con suplemento, Paris 1973).

68 BALIL, A.: «Mosaico con representación de los trabajos de Hércules hallado en Cártama», Varia Boletín de Estudios de Arte y Arqueología 43, 1977, págs. 371- 379; BLÁZQUEZ, J.M.: op. cit. en nota 4, págs. 88- 92

${ }^{69}$ Gozlan, S.: «Au dossier des mosaïques héracléennes: Acholla (Tunisie), Cártama (Espagne), Saint-Paul-Les Romans (Gaule)», RA, 1979, pág. 61.

70 GozLAN, S.: op. cit. en nota 69, págs. 35 ss.

71 Los putti se documentan también en esculturas con un número variable del uno al dieciséis, recuérdese la famosa estatua del Vaticano con 16 putti, que era la altura ideal de crecida para que el Nilo aportase su riqueza, BonnEAU, D.: La crue du Nil, divinité égyptienne à travers mille ans d'histoire (332 av.- 641 ap. J. C.), Paris 1964 págs. 337- 345.

72 Bonneau, D.: op. cit.en nota 71, págs. 104- 109; MeYeR, B.: «L'eau du Nil d’après Prosper Alpin», $B C H$, Suppl. XXVIII, 1994, págs. 121-128. 
brazos hacia Ponto, iconografía que sigue las monedas, bronces y entalles de Asia Menor y Oriente Próximo ${ }^{73}$.

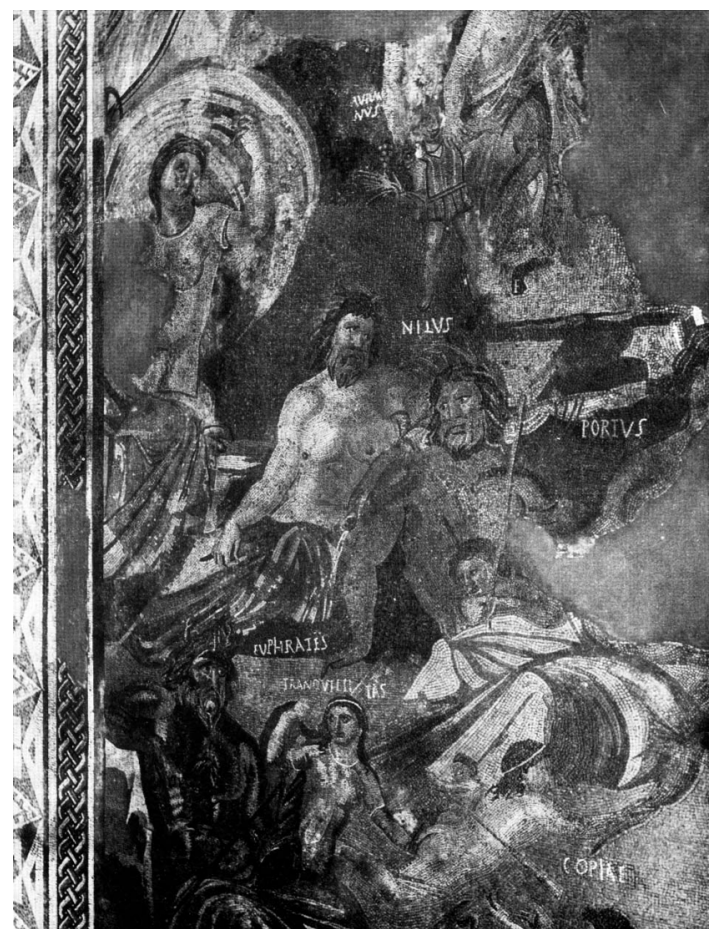

Fig. 12- Mosaico Cosmológico de Augusta Emerita. Segunda mitad del siglo $॥$.

El dios- río Nilo también esta representado en el cuadro central de un mosaico de la villa de Fuente Álamo (Córdoba), datado en el siglo IV ${ }^{74}$; aparece medio tendido y apoyado en una vasija, junto a un hipopótamo, un cocodrilo y dos zancudas. La posición del dios es la más habitual dentro de su iconografía, cuyo ejemplar más antiguo está considerado el fresco de Villa Farnesina de Roma, datado entre los años 25 y 19 a.C., mientras que los animales, cocodrilo e hipopótamo se encuentran esencialmente en las monedas ${ }^{75}$ y la representación de las zancudas está considerada como un símbolo de vida realzando por tanto la idea de prosperidad y fertilidad del río. En una de las lunetas del mosaico de La Metamorfosis de la villa im-

73 En estas obras artísticas Orontes suele aparecer con aspecto también joven, solo o acompañado de Antioquía, LIMC Is. v. «Antiocheia»; LIMC III s. v. «Axios»; LIMC IV s. v. «Fluvii».

74 Daviault, A. et alii, Un mosaico con inscripciones. Une mosaïque à inscripcions. Puente Genil (Córdoba). en Publicacions de la Casa de Velázquez. Série Etudes et Documents, III, Madrid 1987; SAN Nicolás Pedraz, M.P.: «Mosaicos y espacio en la villa romana de Fuente Alamo (Córdoba)», L'Africa Romana X , 1994, págs. 1289- 1304.

75 JENTEL, M.O.: «La représentation du dieu Nil sur les peintures et les mosaïques et leur contexte architectural», Echos du Monde Clasiquel Clasical Views XXXI 6, 1987, pág. 210. 
perial de Carranque, Toledo, del siglo Iv ${ }^{76}$ (Fig. 13), se representa el instante mismo en que Pyramo se transforma en río que tiene sus piernas la forma de una corriente de agua, mientras que Thisbe huye de una tigresa, episodio que relata Ovidio (Met., IV, 55- 166) y Nonnos de Panópolis (Dion., VI, 347- 355; XII, 84- 85) y otros autores sobre los amores del río de Cilicia con Thisbe y su metamorfosis ${ }^{77}$. Otros pavimentos con figuras de ríos no identificados son el de la Casa del Planetario de Itálica, fechado en el siglo $~^{78}$, con su iconografía usual, reclinado en una vasija que mana agua y llevando una cornucopia, imagen que tiene intrínsicamente su propio
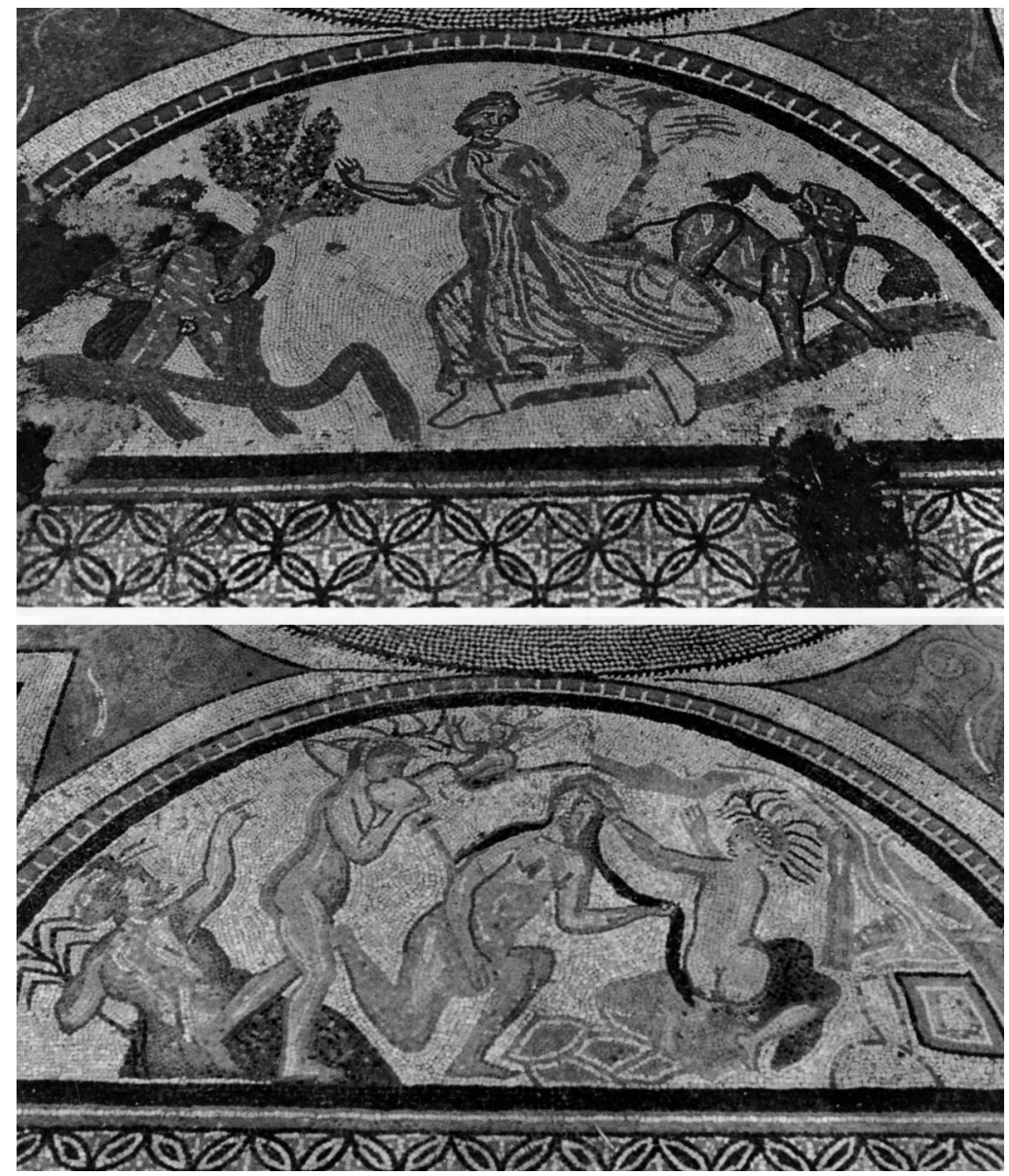

Fig. 13- Mosaico de La Metamorfosis de la Villa de Carranque (Toledo): Pyramo y Thisbe, Baño de Diana. Siglo IV.

${ }^{76}$ ARCE, J.: «Mosaico de La Metamorfosis de Carranque (Toledo)», Madrider Mitteilungen 27, 1986, págs 368- 370, lám. 71a.

77 LIMC VII s. v. «Pyramo et Thisbe»

78 Torres Carro, M.: op. cit. en nota 5, págs. 126- 130. 
concepto acuático. Y la luneta del Baño de Diana del mosaico de Carranque ${ }^{79}$, en donde aparece desnudo y coronado de follaje señalando a Acteón, posiblemente, teniendo en cuenta la historia representada, esta imagen alegórica del dios-río este en relación con la diosa como «señora de las aguas y de las ninfas» ${ }^{80}$.

\section{Fuentes}

En la musivaria hispana están representadas Hipocrene y Amymone. La primera brotó, según la leyenda, al golpear Pegaso con una de sus pezuñas la tierra, por lo que se conoce también con el nombre de la «Fuente del Caballo» y estaba consagrada a las Musas ${ }^{81}$. Aparece en la villa de Almenara de Adaja (Valladolid) en el contexto del mosaico de la «Toilette de Pegaso» del siglo IV ${ }^{82}$, como una figura femenina recostada sobre una roca al pie del monte Helicón (Fig. 14). La ninfa Amymone, que fue transformada en fuente por Neptuno y como tal es citada por los autores antiguos (Apoll. II, 14; Hyg. Fab. 169), figura en el pavimento de Las Metamorfosis de la villa de Carranque (Fig. 15). Ambos mosaicos se fechan en el siglo IV.

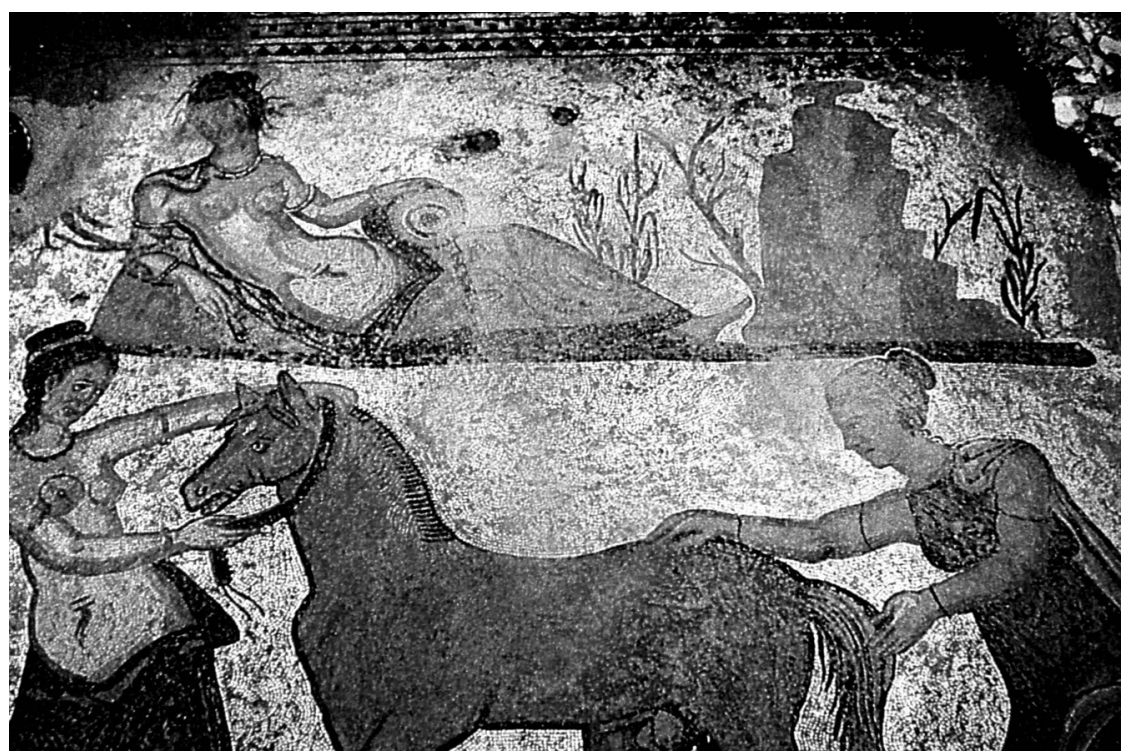

Fig. 14- Mosaico de la «Toilette de Pegaso» de la Villa de Almenara de Adaja (Valladolid).

Siglo IV

79 ARCE, J.: op. cit. en nota 76, pág. 367, lám. 72a.

80 MoRIzot, I.: «Artémis, l'eau et la vie humaine», BCH, Suppl. XXVIII (1994) 202.

81 LIMC VII, S. v. «Pegasos»

82 MAÑNANES, T.: La villa romana de Almenara-Puras (Valladolid), Valladolid 1992, pág. 70; NeIRA, L. y MAÑANES, T.: Mosaicos romanos de Valladolid, CMRE XI, Madrid 1998, págs. 29- 35, nº 15. láms. 11- 12, 31- 34 . 


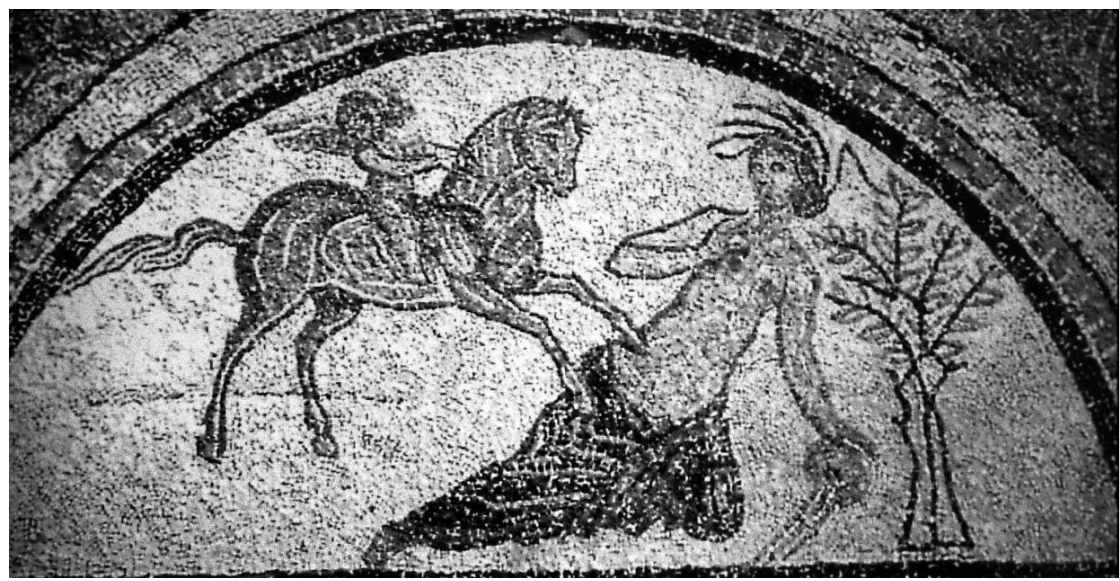

Fig. 15- - Mosaico de La Metamorfosis de la Villa de Carranque (Toledo): Ninfa Amymone. Siglo IV.

\section{Ninfas}

Se identifica a la ninfa Metope, madre de Egina, en el pavimento perdido de Fernán Nuñez (Córdoba), ya citado, dentro del episodio mitológico del rapto de su hija (Fig. 16). Esta representación constituye un unicum en la musivaria romana.

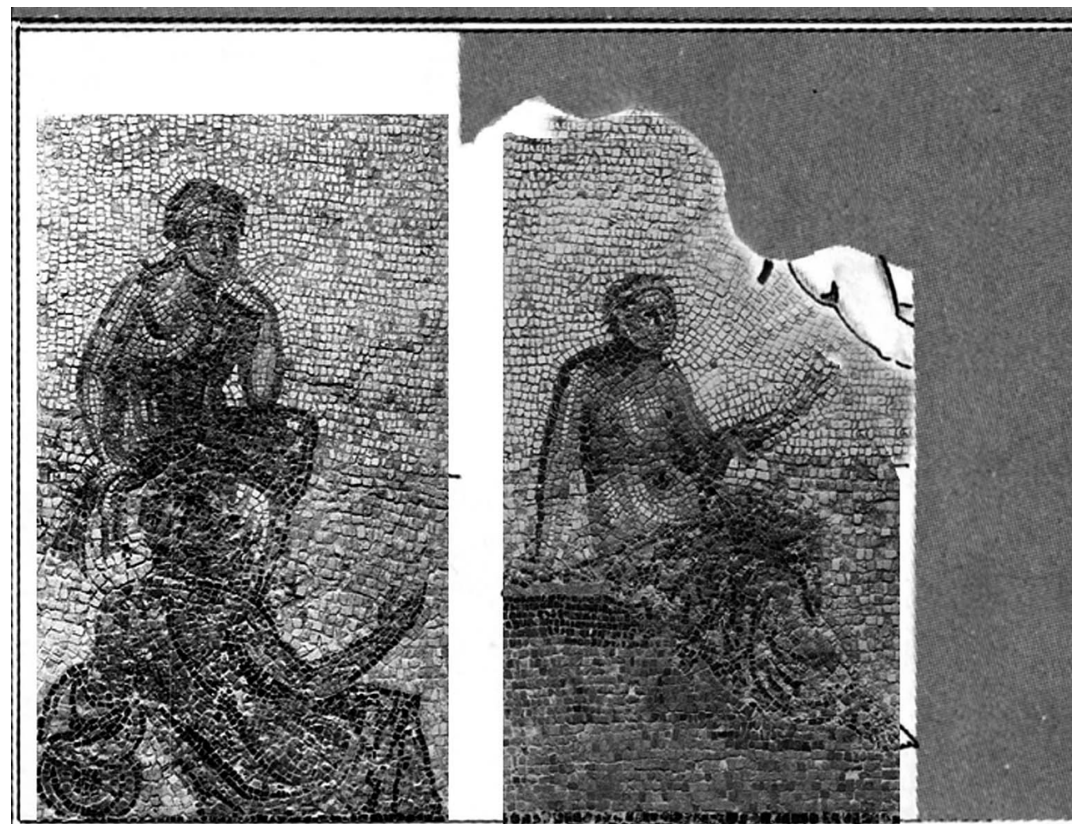

Fig. 16- Mosaico con la ninfa Metope en el Mosaico de Fernán Nuñez (Córdoba). Finales del siglo III. 
Las ninfas Amymone y Aretusa con sus nombres, la última con la iconografía de una nereida, figuran en el citado mosaico del Nacimiento de Venus de Itálica. En el mosaico perdido de Osuna (Sevilla), también ya citado, aparece, junto al río Aqueloo y las sirenas, una figura femenina con la inscripción «NYMPHE» que se ha identificado como la ninfa Amaltea.

Tras el análisis de los mosaicos en estudio, podría decirse que los mosaicos hispanos con las representaciones de seres mitológicos y figuras alegóricas en relación con el agua tienen su dispersión geográfica preferentemente en la Bética (provincia muy romanizada y que pronto tuvo carácter senatorial) y la Lusitania y en puntos aislados del levante y la mitad norte peninsular. En cuanto a sus contextos arquitectónicos corresponden a ambientes termales de carácter urbano, públicos o privados, y de carácter rústico, así como a fuentes o estanques; igualmente se encuentran decorando estancias de prestigio de las casas privadas o de las villae, especialmente en o cerca del triclinium, oecus, tablinum, atrium, peristylum o de los cubicula.

La cronología de estos mosaicos abarca desde el siglo II hasta el V, con un predominio de ejemplares en el Alto Imperio sobre la época Tardorromana. El ejemplar más antiguo de todos estos mosaicos es el de los tritones de la plaza de San Miguel de Barcelona, de tradición italiana, realizado en blanco y negro, que data de la primera mitad del siglo II y que pavimentaba unas termas públicas.

\section{CATALOGO}

1.- ITALICA. Mosaico blanco y negro de una estancia termal de la ciudad. Pavimentaba el espacio contiguo a una piscina con restos de una escalera y próximo a dos salas con hipocaustum en la ínsula comprendida entre la Casa de la Exedra y la Casa de los Pájaros. Representación del Triunfo de Neptuno rodeado por su thiasos marino (peces variados, delfines, ketos, felino marino, carnero marino, toro marino...). El dios guía su carro tirado por dos hipocampos avanzando hacia la derecha. Segunda mitad del siglo II. In situ. BLANCO, A. Y LUZÓN, J.M.(1974); TORRES CARRO, M. (1990), págs. 114-115; DURÁN, M. (1993), págs. 226-263; NEIRA, M.L. (1996), pág. 567, lám. VII,2.

2.- AUGUSTA EMERITA. Fragmentos de un mosaico blanco y negro hallado en una casa romana de la actual calle de Pizarro de Mérida. Representación del Triunfo de Neptuno (hoy desaparecido) rodeado por su thiasos, del que se conserva nereidas sobre un hipocampo, tritones, varios peces y un caballo marino. Principios del siglo III. Museo Nacional de Arte Romano de Mérida. BLANCO A. (1978b), págs. 29- 30, n 7, láms. 8- 10; TORRES CARRO M. (1990), págs. 115116, $121-122$.

3.- PUIG DE CEBOLLA (Sagunto, Valencia). Mosaico polícromo hallado en la villa romana. Representación del Triunfo de Neptuno, hoy desaparecido, carente de 
cortejo marino. Finales del siglo III. BALIL, A. (1966), págs. 336- 340. LABORDE, A. (r. 1975), pág. 265, dibujo no 40; NEIRA, M.L. (1996), pág. 561- 562, lám. III, $1 \mathrm{a}-1 \mathrm{~b}$.

4.- TARRACO. Mosaico con el Triunfo de Neptuno, hoy desaparecido DURÁN, M. (1993), págs. 226 y 262.

5.- SABADELL (Barcelona). Fragmento de un mosaico blanco y negro hallado en la colina de la villa romana de la Salud, próxima a Sabadell, posiblemente en una estancia termal. Neptuno de pie y de frente, con cetro en la mano izquierda y un tridente en la derecha. A su lado izquierdo aparece una tritonesa con el pelo erizado que se sujeta al mango del tridente. Finales del siglo II- principios del III. Museo de Historia de la ciudad de Sabadell. BARRAL X. (1978): págs. 136- 138, $\mathrm{n}^{\circ}$. 147, láms. XCV- XCVI; NEIRA JIMÉNEZ, M.L. (1997), págs. 482 y 485.

6.- SIN PROCEDENCIA. Fragmento de un mosaico polícromo. Dentro de un círculo aparece Neptuno de pie, en actitud de andar, con la cabeza girada hacia atrás, llevando un tridente en su mano derecha y un delfín en la izquierda. Colección Martí Esteve, Servicio de Investigaciones Arqueológica Municipal de Valencia (SIAM). CASTELL, V. (1976), pág. 11; RIBERA, A. (1984), pág. 43; PASIES OVIEDO, T. (2004), pág. 203, fig. 295 (Agradezco a la autora el haberme dejado consultar su Tesis Doctoral todavía inédita).

7.- LA MALENA (Azuara, Zaragoza). Mosaico polícromo de una estancia de prestigio de la villa romana. Neptuno aparece de pie junto a otras divinidades en las bodas de Cadmo y Harmonia. In situ. Siglo IV-V. ROYO J.I. et alii (1991), págs. 209- 221; FERNÁNDEZ GALIANO, D. (1992), págs. 162- 177.

8.- CÁRTAMA (Málaga). Mosaico polícromo con el Nacimiento de Venus. La diosa se encuentra reclinada dentro de la concha, debajo nadan dos delfines afrontados. Finales del siglo II. Museo de Bellas Artes de Málaga. BLÁZQUEZ, J.M. (1981), págs. 85- 88, láms. 70- 71; SAN NICOLÁS PEDRAZ, M.P. (1994), pág. 393, fig. 1.

9.- ITALICA. Mosaico polícromo del tablinum de la Casa del Nacimiento de Venus. Aparece el Nacimiento de Venus en donde figura la diosa sobre una concha sostenida por dos tritones, así como las ninfas Amymone y Aretusa, identificadas por sendas inscripciones, eros, Cronos-Saturno, Urano-Caelum, hipocampos, toro marino, peces. Siglo III. In situ. CANTO A. (1976), págs. 293- 338, láms. XVXVIII; SAN NICOLÁS PEDRAZ, M.P. (1994), pág. 394, fig. 3.

10.- LA QUINTILLA (Lorca, Murcia). Nacimiento de Venus, la diosa aparece recostada sobre una gran concha sostenida por dos tritones, uno joven e imberbe y el otro maduro y barbado. Coronando la composición aparecen en la parte superior de la escena dos erotes que sujetan con ambas manos los extremos de un velo; en la parte inferior dos peces. Siglo IV. Destruido, se conoce por un dibujo. BLÁZQUEZ J.M. (1982), págs. 62- 63, fig. 21; RAMALLO J.F. (1985), pág. 95; SAN 
NICOLÁS PEDRAZ, M.P. (1994), pág. 393, fig. 2; RAMALLO J.F. et alii (2005), págs. 1008-1009.

11.- BRUÑEL (Jaén). Mosaico polícromo de la villa romana. Representación de la diosa Tethys en busto, adornada con patas de cangrejo y un pez serpentiforme en el cuello. Segunda mitad del siglo III o principios del IV. Museo Provincial de Bellas Artes de Jaén. BLÁZQUEZ J.M. (1981), pág. 64, nº. 43, lám. 52; FERNÁNDEZ GALIANO D. (1982), pág. 17.

12.- MARROQUÍES ALTO (Jaén). Mosaico polícromo con la representación de Tethys, adornada como la de Bruñel, pero con un ala o aleta detrás de la cabeza y situada entre dos kethoi y rodeada por delfines, peces diversos y una concha; también aparece un remo a la izquierda de la diosa. Segunda mitad del siglo IV. Museo Provincial de Bellas Artes de Jaén. BLÁZQUEZ J.M. (1981), págs. 59- 60, n 37, láms. 44-45.

13.- COMPLUTUM. Mosaico polícromo de la Casa de Aquiles. En uno de los recuadros de este pavimento aparece una cabeza femenina que ha sido interpretada como Thetis, madre del héroe. Principios del siglo III. Museo Arqueológico Nacional. FERNÁNDEZ GALIANO, D. (1984), págs. 60- 61, láms. XXXI y L.

14.- BARCINO. Fragmentos de un mosaico blanco y negro de unas termas de la ciudad, que sirvió más tarde de pavimento de la antigua iglesia de San Miguel de Barcelona. Figuras de un thiasos marino: icthiocentauros, centauros marinos, hipocampo, delfines, peces, cangrejo. Mediados del siglo II. Museo Arqueológico de Barcelona. BALIL A. (1960), 21- 74; BARRAL X. (1978), págs. 39- 43, nº 7 , láms. XII- XIV.

15.- SANTA VICTÓRIA DO AMEIXIAL (Concelho de Estremoz, Portugal). Mosaico polícromo de una estancia termal de la villa romana. El conjunto está organizado en forma de un cuadrado central rodeado de cuatro franjas rectangulares que encuadran escenas figurativas muy variadas. En el cuadro central de esquema a compás presenta en uno de los círculos una nereida sobre un monstruo marino (pantera), une eros y peces; en otro círculo otra figura femenina sobre un toro marino. En el panel Este, de forma rectangular, se representa un cortejo, compuesto por dos parejas de nereidas cabalgando sobre un ictiocentauro. Siglo IV. Actualmente se encuentra en restauración. TORRES CARRO M. (1978), págs. 89- 102; NEIRA, M.L. (1991), págs. 516- 524, figs. 7- 8.

16.- CASARICHE (Sevilla). Mosaico polícromo de esquema de compás. El círculo central lo ocupa la cabeza de Océano. En las esquinas una crátera y en los laterales cuatro semicírculos con hipocampos y tritones portando un pedum. Primera mitad del siglo III. Colección Santos en Madrid. MONDELO, R. y TORRES CARRRO, M. (1985), págs. 143- 155, láms. I-II.

17.- EL CHORREADERO (Paterna, Cádiz). Tres fragmentos de un mosaico blanco y negro que rodeaba la fuente o surtidor escalonado de un estanque, situado en el centro de un patio de la villa romana. Estaría representado un thia- 
sos marino del que se conservan varios icthiocentauro, uno de ellos soplando una caracola que sostenía con la mano izquierda y portando en la otra un gran timón, además de un delfín, un monstruo marino identificado con un grifo. Primera mitad del siglo II. Museo Arqueológico y de Bellas Artes de Cádiz. CORZO, R. (1981-82), págs. 51- 54; BLÁZQUEZ, J.M. (1982), págs. 52-53, nº 4849, láms. 15, 20-21.

18.- $L A C O C O S A$ (Badajoz). Fragmento de un mosaico polícromo del tepidarium de las termas de la villa romana. Estaría representado un thiasos marino del que se conserva un icthiocentauro portando un timón y soplando una caracola, además de varias especies de animales marinos como una murena hellena. Principios del siglo IV. Museo de la Diputación de Badajoz. SERRA Y RÀFOLS, J. de C. (1952), págs. 79- 82; ALVAREZ, J.M. (1983), págs. 379- 388, láms. I- II; NEIRA, M.L. (1991), págs. 516, 519- 520 y 524, lám. 5.

19.- CONIMBRIGA (Portugal). Mosaico polícromo de la estancia central del ala sur del peristilo de la Casa de los Surtidores. Tritón portando en su brazo izquierdo un vexillum y en la mano derecha un delfín. En la parte inferior nadan tres peces, uno de ellos es un delfín. En el resto del mosaico grifos y aves encerrados en círculos de hojas de laurel. Finales del siglo II- principios del III. In situ. BAIRRAO OLEIRO, J.M. (1965), págs. 257, 260-263; LÓPEZ MONTEAGUDO, G. (1990), págs. 209-210, fig. 7; BAIRRAO OLEIRO, J.M. (1992), págs. 84-87.

20.- SASAMÓN (Burgos). Mosaico polícromo de la mansio Segisamo, en un lugar denominado Arquillo, fuera del núcleo urbano, con una composición geométrica. En el octógono central esta representado un personaje marino en busto y con dos pinzas de cangrejo en la cabeza, que se ha interpretado como un tritón, iconografía única en este tipo de representaciones. Los octógonos laterales van decorados con otros animales marinos: ciervos, caballo, grifo, pantera. En los hexágonos figuran peces y distintas clases de pájaros, mientras que en el resto de las figuras geométricas aparecen motivos florales, cruces griegas y nudos de Salomón. Finales del siglo II- comienzos del III. Se conserva en la Iglesia Parroquial de Sasamón. ABÁSOLO, J.A. y GARCÍA, R. (1993), págs. 179- 192, fig. 95, láms. XIXXXVI; TORRES CARRO, M. (1990), págs. 110- 114; LÓPEZ MONTEAGUDO, G. et alii (1998), pág. 32, n. 159, fig. 8, láms. 19-20 y 44.

21.- CÓRDOBA. Mosaico polícromo procedente de un lugar indeterminado de la Colonia Patricia Corduba. El octógono central está decorado con la cabeza de Océano. En torno al octógono, ocupando varios rectángulos, aparecen figuras alternadas de tritones y genios que brotan de plantas. Museo Arqueológico de Córdoba. MARCOS POUS, A.- VICENT ZARAGOZA, A.M. (1985), pág. 244 y fig.; LÓPEZ MONTEAGUDO, G. (2006b), págs. 499- 500; LÓPEZ MONTEAGUDO, G. (en prensa).

22.- CANAMA (Alcolea del Río, Sevilla). Mosaico polícromo con tritones dispuestos alrededor de una cabeza de Gorgona situada en el emblema central. Pri- 
mera mitad del siglo III. Perdido. CAMPOS, M. (1896), pág. 16; NEIRA, M.L. (1994), pág. 366; NEIRA, M.L. (1998), págs. 223-346.

23.- EL POMAR (Badajoz). Mosaico polícromo de esquema a compás. Situado en la estancia central del frente septentrional de la villa romana, próxima a Jerez de los Caballeros, posiblemente un oecus con función de triclinium. Estaría representado un thiasos marino del que se conserva en uno de los semicírculos un tritón portando un remo. El círculo central lo ocupa la figura de un auriga victorioso. Primera mitad del siglo IV. Alcazaba de Mérida. ALVAREZ, J.M. (1989), págs. 341351, láms. 74-82; NEIRA, M.L. (1991), pág. 514, fig. 1.

24.- ITALICA, Santiponce, Sevilla. Fragmentos de un mosaico polícromo que pavimentaba una fuente o estanque. Cuatro tritones jóvenes e imberbes en torno a un espacio central, destruido, portando variados atributos como el pedum y la pardalis. Primera mitad del siglo III. Museo Arqueológico de Sevilla. BLANCO, A. (1978a), págs. 32-34, láms. 20-27; CAMPOS, M. (1897), págs. 14-17; TORRES CARRO, M. (1990), págs. 110- 112, 123-124; NEIRA, M.L. (1994), pág. 366.

25.- MILREU (Algarve, Portugal). Fragmento de un mosaico polícromo, podium del santuario (nymphaeum) de la villa romana, que se conoce por un dibujo del siglo XIX. Dos tritones enfrentados, además de varios peces. Siglo IV- V. Dibujo en el Museo de Lisboa. ALMEIDA, F. de (1962), pág. 233, lám. 53; SOARES DOS SANTOS, A.R (coord.). (2005), pág. 26; FEICHNER, F. (2006), págs. 213-214, fig. 8.

26.- FUENTE ALAMO (Córdoba). Mosaico polícromo posiblemente de una estancia termal de la villa romana, en una zona muy próxima al famoso mosaico Nilótico infra $\mathrm{n}^{\circ} 52$. En el mosaico, hoy desaparecido y conocido por un dibujo, aparecía un tritón, un caballo marino y en la parte central una nave, así como varias figuras muy deterioradas. Siglo IV. SAN NICOLÁS PEDRAZ, M.P. (1994), pág. 1289 , nota 4.

27.- AMPURIAS (Gerona). Mosaico en blanco y negro. Termas públicas de la insula 30, apodyterium o la cella unctuaria. En el medallón central aparece un tritón y un delfín, mientras que losángulos están decorados con otros animales fantásticos. Siglo I a.C.- I d.C. AQUÍLUÉ, X. et alii (2002), págs. 241-260, figs. 7 y 8.

28.- DUEÑAS (Palencia). Mosaico polícromo del tepidarium de las termas de la villa romana. Dos nereidas situadas a ambos lados de la máscara de Océano. La de la derecha del dios se encuentra sentada sobre la cola pisciforme de un toro marino y porta un cesto de frutos. La de la izquierda, de espaldas al espectador, está sentada sobre la cola pisciforme de una pantera y sujeta una phiale con ambas manos. Se data en torno al año 330. Colección privada. PALOL, P. (1963), págs. 1- 30; PALOL, P. (1967), págs. 196- 230; NEIRA, M.L. (1991), págs. 516, 520- 521, 524, fig. 6

29.- ASTIGI (Écija, Sevilla). Fragmento de un mosaico polícromo de las termas privadas de una domus. Dos nereidas sobre sendos monstruos marinos, una de 
ellas reclinada sobre la espalda de una pantera marina. Siglo II- III. Museo de Écija (Sevilla). GARCÍA- DILS, S. et alii (en prensa).

30.- CARMONA (Sevilla). Fragmento de un mosaico polícromo de la Oficina urbana de El Monte. Nereida cabalgando un hipocampo rodeada de Eros navegando sobre un ánfora, un pez y un bivalvo. Siglo II- III. CARTAYA BAÑOS, J. (2001), págs. 293- 309, figs. 16 y 18.

31.- ITALICA. Fragmentos de un mosaico polícromo. Nereida cabalgando sobre un monstruo marino. Perdido, se conoce por un antiguo dibujo. Siglo II-III. CELESTINO, S. (1977), págs. 366- 370, lám. XXVI; NEIRA, M.L. (1991), pág. 517, nota 29.

32.- CÓRDOBA. Mosaico polícromo de Polifemo y Galatea, la cual está sentada sobre un kethos. Triclinium. Principios del siglo III. Alcazar de los Reyes Cristianos de Córdoba. BLÁZQUEZ, J.M. (1981), págs. 13- 17, nº 1, fig. 1-2, láms. 1-2, 81.

33.- DEHESA DEL HINOJAL (Mérida). Mosaico polícromo de una estancia termal de la villa romana próxima a la ciudad de Augusta Emerita. Nereida sobre un Kethos marino. Segundo cuarto del siglo IV. Museo Nacional de Arte Romano de Mérida. ALVAREZ, J.M. (1976), págs. 450-451, 456-457, 462-463, fig. 3, láms. XIXII; BLANCO, A. (1978b), pág. 51, n. 63, láms. 93b- 94a; M.L. Neira (1991), págs. 515- 524, fig. 4.

34.- ILLICI (Elche, Alicante). Dos fragmentos de un mosaico polícromo de la galería A de la villa romana de Algorós, cerca de Illici. La nereida Galatea, semidesnuda, nimbada e identificada con su nombre en letras capitales, aparece sentada sobre un hipocampo. Se data en torno al año 330. Museo Arqueológico Nacional (frag. de la nereida) y Museo Municipal A. Ramos Folqués de Elche (frag. con la inscripción). ABAD, L. (1985), págs. 369-370); MONDELO, R. (1985), págs. 107- 141; BLÁZQUEZ, J.M. et alii, (1989), págs. 35- 37, n. 17, fig. 17, láms. 18 y 40; NEIRA, M.L. (1991), págs. 515- 516 y 520- 524, figs. 3 y 9.

35.- POMPAELO. Fragmentos de mosaico blanco y negro con murallas, caballo marino y restos de otros animales. Siglo II-III. Museo de Navarra BLÁZQUEZ, J.M. y MEZQUIRIZ, M.A. (1985), págs. 55- 56, nº 35, lám. 34. SAN NICOLÁS PEDRAZ, M.P. (2004), pág. 833, fig. 11.

36.- CIELLA. Fragmento de esquina de un mosaico polícromo con un hipocampo alado, iconografía poco usual en la musivaria romana. In situ. LÓPEZ MONTEAGUDO, G. et alii, (1998), pág. 38, nº 17, láms. 21 y 45.

37.- CÓRDOBA. Mosaico blanco y negro de una fuente. Representación de un thiasos marino con fauna real (besugos, delfines, angulas, moluscos y crustáceos) y fantástica (kethos, caballo, mula pantera). Siglo II. Se conservaba en una fuente pública de la Avenida del Dr. Fleming de Córdoba. Actualmente se encuentra en el Museo Arqueológico de Córdoba. BLÁZQUEZ, J.M. (1981), pág. 19, nº 4, láms. 3- 7, láms. 3- 6. 
38.- CÓRDOBA. Fue hallado en el Cortijo del Alcalde, a $3 \mathrm{~km}$. de la ciudad. Mosaico en blanco y negro con la representación de un thiasos marino: delfines, besugos, peces-espada, caballos, cabras, kethos. Siglo II. Museo Arqueológico de Córdoba. BLÁZQUEZ, J.M. (1981), pág. 48, nº. 28, láms. 37- 38.

39.- ILLICI. Fue hallado en la finca de Don R. Irles, a medio kilómetro de La Alcudia (Elche), conocida como «casa de las tejas», posiblemente una villa de prestigio. Mosaico blanco y negro con animales diversos en compartimentos (monstruo marino, ave, pez) y una máscara de Océano en un friso exterior, mientras que en el emblema central hay restos de una escena de caza. Siglo II. Museo de La Alcudia de Elche. ALBERT, J. (1945), págs. 340-342; RAMOS FOLQUÉS, A. (1970), págs. 55-56; RUIZ, E. (2001), págs. 45-49.

40.- ILLICI. Hallado junto al anterior. Mosaico polícromo con motivos vegetales y la representación de un hipocampo. Siglo III. Museo de La Alcudia de Elche. RAMOS FOLQUÉS, A. (1970), pág. 56; RUIZ, E. (2001), pág. 48, fig. 8.

41.- SIN PROCEDENCIA. Mosaico en blanco y negro. Dentro de un círculo aparece un hipocampo. Fue adquirido por el Museo de Lisboa a un anticuario de la ciudad. SOARES DOS SANTOS, A.R (coord.) (2005) pág. 22.

42.- CARRANQUE (Toledo). Mosaico polícromo de una fuente del peristilo de la villa, situada enfrente de la entrada al triclinium. Pantera marina, peces y almejas alrededor de Océano que preside la composición. FERNÁNDEZ-GALIANO, D. (1994), pág. 324, fig. 6; LÓPEZ MONTEAGUDO, G. (2006b), págs. 501- 502; LÓPEZ MONTEAGUDO, G. (en prensa).

43.- MADRIGALEJO (Cáceres). Mosaico polícromo, seguramente localizado en las termas. En el centro, dentro de un óvalo, una máscara de Océano, mientras que en los ángulos figuran peces (ballenas) y en los cuatro centros laterales del cuadro dragones e hipocampos. BRAH 10, 1887, págs. 165-168; MÉLIDA, J.R. (1924), págs. 178- 179.

44.- CONIMBRIGA (Portugal). Mosaico polícromo de la estancia central del S.O. del peristilo de la Casa de los Surtidores. Kethos con Perseo y la Medusa. In situ. LÓPEZ MONTEAGUDO, G. (1990), págs. 203-204, fig. 3; BAIRRAO OLEIRO, J.M. (1992), pág. 32-36; LÓPEZ MONTEAGUDO, G. (1998a), págs. 454-455, fig. 14.

45.- TARRACO. Mosaico polícromo. Kethos ya muerto entre Perseo y Andrómeda. Época severiana. BALIL, A. (1969), págs. 3-12, láms. I-III; LÓPEZ MONTEAGUDO, G. (1998a), págs. 462-467, fig. 22.

46.- ASTIGI (Écija). Mosaico polícromo de los Raptos de Europa y Ganímedes. En este pavimento aparece una cabeza que emerge del agua, con abundante cabellera y orejas leoninas, que ha sido interpretado como un daimon. Siglo II- III. Museo de Écija. LÓPEZ MONTEAGUDO, G. y SAN NICOLÁS PEDRAZ, M.P. (1995), págs. 420-423, fig. 36; LÓPEZ MONTEAGUDO, G. (1998), págs. 38-51; LÓPEZ MONTEAGUDO, G. (2001), págs. 132-134, lám. IV. 
47.- CÓRDOBA. Mosaico polícromo de la villa romana de Fernán Nuñez. Perdido. El dios río-Asopo dentro del episodio del rapto de su hija Egina por Zeus. Siglo III. FERNÁNDEZ GALIANO, D. (1982), pág. 19, fig. 1; SAN NICOLÁS PEDRAZ, M.P. (2005, en prensa).

48.- ITALICA. Mosaico polícromo de los Amores de Zeus, hallado en una casa de la ciudad. En uno de los rectángulos curvos aparece el dios-río Asopo en el momento de hacer brotar la fuente Pirene en la ciudad de Corinto. Finales del siglo II o comienzos del III. Casa de la Condesa de Lebrija, Sevilla. MANJÓN, R. (1915), págs. 235- 242; BLANCO, A. (1978a), págs. 25- 26, láms. 1-7; FERNÁNDEZ GALIANO, D.: (1982), pág. 19; SAN NICOLÁS PEDRAZ, M.P. (2005, en prensa).

49.- OSUNA (Sevilla). Mosaico polícromo. Personificación del dios-río Aqueloo, sentado y apoyado en una urna, con un solo cuerno en la frente e identificado con su nombre. También aparece bustos femeninos y las inscripciones sire(ne) y nymphe. Segunda mitad del siglo III. Perdido. THOUVENOT, R. (1940), págs. 645- 646, (reimp. con suplemento, Paris 1973).

50.- CÁRTAMA (Málaga). Mosaico polícromo de Los trabajos de Hércules. Personificación del dios-río Aqueloo, sentado sobre un promontorio, carece de cuerno y está identificado con su nombre. Principios del siglo III. Se conserva en un cementerio próximo a Bilbao. BALIL, A. (1977), págs. 371- 379; BLÁZQUEZ, J.M. (1981), págs. 88- 92.

51.- AUGUSTA EMERITA. Mosaico Cosmogónico, polícromo. Hallado junto al atrium tetrastilo de la Casa de Mitreo. Personificaciones de los dioses-ríos Éufrates, Nilo y Orontes. Posiblemente también estaría representada la diosa Tethys en contraposición a la figura de Océano. Segunda mitad del siglo II. BLANCO A. (1978b), fig. 1, láms. 36-37; QUET M.H. (1981); BLÁZQUEZ J.M. (1986), págs. 89- 100; FERNÁNDEZ GALIANO D. (1989- 1990), págs. 173- 182.

52.- FUENTE ALAMO (CÓRDOBA). Mosaico polícromo de la estancia cruciforme de la villa romana. La personificación del dios-río Nilo junto a un hipopótamo, un cocodrilo y dos zancudas. Siglo IV. In situ. DAVIAULT, A. et alii, (1987); SAN NICOLÁS PEDRAZ M.P. (1994), págs. 1289- 1304.

53.- ITALICA. Mosaico polícromo de la Casa del Planetario. Personificación de un dios-río sentado en el suelo. Siglo II. In situ. TORRES CARRO, M. (1990), págs. 126- 130.

54.- CARRANQUE (Toledo). Mosaico polícromo de Las Metamorfosis del $\mathrm{Cu}$ biculum principal de la villa romana. En una de las lunetas aparece la ninfa Amymone que se aparta asustada de Poseidón metamorfoseado en caballo, montado por eros. En otra luneta Píramo se está transformando en río, mientras que Tisbe huye de una tigresa. También en otra luneta aparece un dios-río señalando con el dedo a Acteón. In situ. Siglo IV. ARCE J. (1986), págs. 368- 370, lám. 71a; pág. 367, lám. 72a. 
55.- ALMENARA DE ADAJA (VALLADOLID). Mosaico polícromo de la sala octogonal de la villa romana. La personificación de la fuente Hipocrena en el monte Helicón (Beocia) observando la «toilette de Pegaso». Siglo IV, In situ. Mañanes T. (1992), pág. 70; NEIRA, L. y MAÑANES, T. (1998), págs. 29- 35, n 15, láms 11 12, 31-34.

\section{BIBLIOGRAFÍA DEL CATÁLOGO}

ABAD, L. (1985): «Arqueología romana del país valenciano: panorama y perspectivas», en Arqueología del País Valenciano, Alicante.

AbÁsolo, J.A. y García, R. (1993): Excavaciones en Sasamón (Burgos), EAE 164, Madrid.

AlBERT, J. (1945): «Descubrimiento de un mosaico en Elche», AEspA 18, págs. 340-342.

AlmeidA, F. de (1962): Arte visigótica em Portugal. O Arqueólogo portugues, Lisboa, Sér. II,4.

AlvareZ, J.M. (1976): «La villa romana de El Hinojal en la Dehesa de las Tiendas (Mérida)», NotArqHisp. IV, Madrid.

AlvareZ, J.M. (1983): «El mosaico del tritón de la villa romana de La Cocosa (Badajoz)», Homenaje al Prof. Martín Almagro Basch III, Madrid, Univ. Complutense, págs. 379-388.

AlvareZ, J.M. (1989): «El mosaico de la villa romana de El Pomar (Jerez de los Caballeros)», Homenaje al Prof. D. A. Blanco, págs. 341- 351.

ARCE, J. (1986): «Mosaico de La Metamorfosis de Carranque (Toledo)», Madrider Mitteilungen 27, págs. 365-374.

BairRão OleIRo, J.M. (1965): «Mosaïques romaines du Portugal, CMGR I, Paris 1965, págs. 257-266.

Bairrão OleIro, J.M. (1992): Conimbriga. Casa dos Repuxos. Corpus dos Mosaicos Romanos de Portugal, Conímbriga.

BaliL A. (1960): «El mosaico romano de la iglesia de San Miguel», Cuadernos de Arq. e Historia de la Ciudad I, págs. 21- 74.

BALIL, A. (1966): «Los mosaicos de la villa romana de El Puig de Cebolla (Valencia)», IX Congreso Arqueológico Nacional (Valladolid 1965), Zaragoza, págs. 336- 340.

BALIL, A. (1969): «ll mosaico della Medusa di Tarragona», Hommages à Marcel Renard III, págs. 3- 13.

BALIL, A. (1977): «Mosaico con representación de los trabajos de Hércules hallado en Cártama», Varia Boletín de Estudios de Arte y Arqueología 43, págs. 371- 379.

BARRAL, X. (1978): Les mosaïques romaines et mediévales de la Regio Laietana, Barcelona.

Blanco, A. (1978a): Mosaicos romanos de Italica, CMRE I, Madrid.

Blanco, A. (1978b): Mosaicos romanos de Mérida, CMRE II, Madrid.

BLANCO, A. y LuZÓN, J.M. (1974): El mosaico de Neptuno en Itálica. Sevilla. 
BLÁZQUEZ, J.M.(1981): Mosaicos romanos de Córdoba, Jaén y Málaga, CMRE III, Madrid.

BLÁZQUeZ, J.M. (1982): Mosaicos romanos de Sevilla, Granada, Cádiz y Murcia, CMRE IV, Madrid.

BLÁZQUEZ J.M. (1986): «Cosmología mitraica en un mosaico de Augusta Emérita», AEspA 59, págs. 89- 100

BLÁZqUEZ, J.M. et alii (1989): Mosaicos romanos del Museo Arqueológico Nacional, CMRE IX, Madrid.

BLÁZQUEZ, J.M. et alii (2004): «Representaciones mitológicas, leyendas de héroes y retratos de escritores en los mosaicos de época imperial en Siria, Fenicia, Palestina, Arabia, Chipre, Grecia y Asía Menor», Antigüedad y Cristianismo (Murcia), págs. 277-371.

BLÁzqUEZ, J.M. y MezquIRIz, M.A. (1985): Mosaicos romanos de Navarra, CMRE VII, Madrid.

Campos, M. (1897): Mosaicos del Museo Arqueológico Provincial de Sevilla, Sevilla.

CANTO A. (1976): «El mosaico del Nacimiento de Venus en Itálica», Habis 7, págs. 293- 338.

CARTAYA BAÑos, J (2001).: «Mosaicos romanos de Carmona», en A Ceballos (ed.), Carmona romana, Carmona, págs. 293- 309,

CASTELL, V. (1976): «De la Valencia romana», Boletín de información Municipal, 3. Valencia.

Celestino, S. (1977): «Mosaicos perdidos de Itálica», Habis 8, págs. 359- 383.

Corzo, R. (1981-82): «Un nuevo mosaico romano de thiasos marino», BMusCád III, pags. 51-54.

Daviault, A. et alii, (1987): Un mosaico con inscripciones. Une mosaïque à inscripcions. Puente Genil (Córdoba). en Publicacions de la Casa de Velázquez. Série Etudes et Documents, III, Madrid.

DURÁn M. (1993): Iconografía de los mosaicos romanos en la Hispania alto-imperial, Barcelona.

FEICHNER, F. (2006): «De lo romano a lo árabe. La transición del sur de la provincia de lusitania a Al- Gharb Al- Andalus. Nuevas investigaciones en los yacimientos de Milreu y Cerro de Vila», Anejos de AEspA XXXIX, págs. 207-220.

FERNÁNDEZ GALIANO, D. (1982): «Nuevas interpretaciones iconográficas a mosaicos hispanos», Museos I, págs. 17-27.

Fernández Galiano, D. (1984): Complutum. II Mosaicos, EAE 138, Madrid.

FERNÁNDEZ GaliANO, D. (1989-1990): «Observaciones sobre el mosaico de Mérida con la Eternidad y el Cosmos», Anas 2/3, págs. 173- 182.

FERNÁNDEZ GALIANO, D. (1992): “Cadmo y Harmonía: imagen, mito y arqueología», Journal of Roman Archaeology 5, págs. 162- 177.

FERNÁNDEZ Galiano, D. (1994):«Mosaicos de la villa de Carranque: un programa iconográfico", VI Coloquio Internacional sobre mosaico antiguo (Palencia-Mérida 1990), Palencia, págs. 317-326.

GARCíA- DıLS, S. et alii: «Mosaicos romanos de Écija (Sevilla). Nuevos hallazgos», $X^{\circ}$ Coloquio Internacional/Aiema. O Mosaico Antigonos centros e nos perife- 
rias: originalidades, influencias e identidades (Conimbriga, Portugal 2005), en prensa.

LABORDE, A. (r. 1975): Viatge pintoresc i històric. El País Valencià i les Illes Balears. (Original de 1806 editado en Paris). Valencia.

LóPEZ MonTEAGUdo, G. (1990): «El programa iconográfico de la Casa de los Surtidores de Conimbriga», Espacio, Tiempo y Forma II/ 3, págs. 199-232.

López MonteAGudo, G. (1998a): «El mito de Perseo en los mosaicos romanos. Particularidades hispanas», Espacio, Tiempo y Forma II/11, 1998, págs. 435- 491

LóPEZ MoNTEAGUDO, G. (1998b): «El simbolismo de la travesía marina en algunos mitos clásicos», Latomus $57 / 1$, págs. 38-51.

LóPez MonTEAGUdo, G. (2006a): «Lo provincial y lo original en los mosaicos romanos. Original versus provincial», en Homenaje a la profesora Pilar León Alonso, Córdoba, págs. 271-292.

LóPez MonteAgudo, G. (2006b): «Oceanus on the Roman Mosaic Pavements of Spain». Proceedings of the Symposium 12 International Conferense 'Cura Aquarum in Ephesus', Leiden págs 497- 503.

LóPEZ MonTEAGUDO, G. (en prensa): «La iconografía del dios Océanos en los mosaicos hispano-romanos", $X^{\circ}$ Coloquio Internacional/Aiema. O Mosaico Antigonos centros e nos periferias: originalidades, influencias e identidades (Conimbriga, Portugal 2005).

LÓPEZ MONTEAGUDO, G. et alii (1998): Mosaicos romanos de Burgos CMRE XII, Madrid. MAÑANES T. (1992): La villa romana de Almenara-Puras (Valladolid), Valladolid.

MANuÓn, R. (1915): «El mejor mosaico de Itálica», Boletín de la Real Academia de la Historia 67, págs. 235- 242.

MÉLIDA, J.R. (1924): Catálogo monumental de España. Provincia de Cáceres (1914- 1916), Madrid.

Marcos Pous, A. y Vicent Zaragoza, A.M. (1985): «Investigació, técnicas y problemas de las excavaciones en solares de la ciudad de Córdoba y algunos resultados topográficos generales», Arqueología de las ciudades modernas superpuestas a las antiguas. Ministerio de Cultura, Madrid.

MONDELO, R (1985): «Los mosaicos de la villa romana de Algorós (Elche)», BSAA LI, 1985, págs. 107-141.

Mondelo, R. y TorRes M. (1985): «El mosaico romano de Casariche (Sevilla)», BVallad LI, págs. 143-157.

NEIRA JIMÉNEZ, M.L. (1991): «Acerca de las representaciones del thiasos marino en los mosaicos romanos tardoantiguos de Hispania», Ant.Crist. VIII, págs. 516- 524.

NeIRA JIMÉNEZ, M.L. (1994): «Mosaicos romanos con nereidas y tritones. Su relación con el ambiente arquitectónico en el Norte de Africa y en Hispania», L'Africa Romana X, 1259- 1278.

NeIRA JiMÉNEZ, M.L. (1996): «La tipología del carro en los mosaicos romanos del triunfo de Neptuno", L 'Africa Romana XI, págs. 555- 591.

NEIRA JIMÉNEZ, M.L. (1997): «Algunas consideraciones sobre mosaicos con nereidas y tritones en ambientes termales de Hispania», en PERÉX, M.J. (ed.), Termalismo Antiguo (I Congreso Peninsular), Madrid, UNED- CV, págs. 481- 496. 
NeIRA JimÉnEZ, M.L. (1998): «Paralelos en la musivaria romana de Grecia e Hispania. A propósito de un mosaico de Alcolea del Río y un pavimento de Mitilene», Anales de Arqueología cordobesa 9, págs. 223- 246.

NeIRA M.L. y MAÑANES, T. (1998): Mosaicos romanos de Valladolid, CMRE XI, Madrid.

PALOL, P. (1963) : «Mosaicos romanos de tema marino en Dueñas (Palencia) », VIII Congreso Nacional de Arqueología (Sevilla-Málaga), págs. 5- 32.

PALOL, P. (1967) : «Das Okeanos-Mosaik in der römischen Villa zu Dueñas (prov. Palencia)», Madrider Mitteilungen 8, págs. 196-225.

Pasies OViedo, T. (2004): Pavimentos musivos e época romana en la comunidad valenciana. Tratamientos y problemáticas asociadas a su conservación y restauración. Tesis Doctoral. Un. Politècnica de Valencia.

QUET M.H (1981): La mosaïque cosmologique de Mérida, Paris.

Ramallo J.F. (1985): Mosaicos romanos de Carthago Nova (Hispania Citerior), Murcia.

RAMALLO, J.F. et alii (2005): «La villa romana de la Quintilla (Lorca, Murcia): análisis de su programa decorativo y ornamental», La Mosaïque Greco-Romaine IX, Roma, págs. 1001-1021.

RAMOS FolquÉs, A. (1970): Historia de Elche. Elche.

RiberA, A. (1984): València romana. Els orígens de la ciutat. Valencia.

Royo J.I. et alii (1991): «Excavaciones en La Malena (Azuara, Zaragoza) $3^{a}$ campaña 1988», Arqueología Aragonesa 1988-89, págs. 209- 221.

RuIz, E. (2001): Los mosaicos de Illici y del Portus Illicitanus, Valencia.

SAN Nicolás Pedraz M.P. (1994): «La iconografía de Venus en los mosaicos hispanos", VI Congreso Internacional del Mosaico Antiguo (Palencia- Mérida 1990), Guadalajara, págs. 393-405.

San Nicolás Pedraz M.P. (1994): «Mosaicos y espacio en la villa romana de Fuente Alamo (Córdoba)", L'Africa Romana X, págs. 1289- 1304.

San Nicolás Pedraz, M.P. (2004): «Mosaicos hispano- romanos con representaciones de murallas", L'Africa Romana XV, págs. 825-852.

San Nicolás Pedraz M.P. (2005, en prensa): « Los Amores de Zeus/Júpiter en los mosaico romanos de Hispania», $X^{\circ}$ Coloquio Internacional/AIEMA (Conimbriga 2005).

SERRA Y RÀFols, J. de C. (1952): La villa romana de La Cocosa, Badajoz, Badajoz. SoARES dos SANTOS, A.R (coord.) (2005): Mosaicos romanos. Nas Colecçoes do Museu Nacional de Arqueologia, Lisboa.

THOUVENOT, R. (1940): Essai sur la province romaine de Bétique, Paris, Boccard, (reimp. con suplemento, Paris 1973).

Torres Carro M. (1978): «La escena de Ulises y las sirenas del mosaico de Santa Vitória», BSAA XLIV, págs. 89- 102.

TorRes CARRo, M. (1990): «Iconografía marina. Mosaicos romanos. Estudios sobre Iconografía». Actas de Homenaje in Memoriam de A. Balil, Madrid, págs.107134. 